\title{
Cristianismo y liberación ¿Revolución en el cristianismo?
}

\author{
Un estudio cubano de la teología de la liberación \\ latinoamericana, de sus condicionamientos \\ y su situación actual.
}

Fernando Martínez Heredia Jefe del Departamento de Estudios Regionales del Centro de Estudios Americanos (CEA). La Habana, Cuba.

En los últimos aflos se ha extendido en América Latina una nueva manera de vivir la religiosidad cristiana y de reflexionar acerca de ella. El tema mismo, por otra parte, ha ido atrayendo de modo creciente el interes de los medios sociales y políticos del continente, desde las comunidades campesinas, de pobladores, sindicatos y partidos o movimientos de liberación, hasta los aparatos represivos de los estados y el propio gobiemo norteamericano. Asistimos a una renovación del papel social y político de la religión que no era previsible o sontable en América de la primera mitad de este siglo. La proximidad del reino y el fin de la dominación capitalista, los textos sagrados y la justicia social, la salvación y la liberación, la teología y la vida del pueblo humilde, se han vuelto topicos afines entre sí, y se busca un auténtico compromiso y solidaridad con los pobres explotados que luchan por su liberación.

¿Qué ha sucedido en la Iglesia, cuyas jerarquías hace apenas 30 aflos bendecían a los "libertadores" que aplastaban a Latinoamérica de Guatemala a Argentina? ¿Qué está cambiando, y esto es mucho más profundo, en la manera de ser creyente y de ser Iglesia en América? ¿Qué lugar y qué perspectivas tienen la teología de la liberación y la Iglesia llamada popular, en la agonía que viven los pueblos y en la imprescindible era de cambios que exige la región? Estas y otras interrogantes muestran muy claramente la necesidad de conocimiento -entre otras necesidades - que tenemos de estas realidades de nuestro tiempo. En buena medida los analistas sociales estamos insuficientemente preparados para plan- 
tearlas bien, no digamos ya para responderlas. Una parte de los cientificos sociales latinoamericanos no parece incluso tomar en cuenta el tema todavia, ausencia de consecuencias más lamentables en el caso de los que están comprometidos con las demandas y las causas populares. Son los intelectuales cristianos los que realizan casi toda la reflexión existente sobre la renovación cristiana y sus perspectivas respecto a la liberación. Sin embargo, por su evidente importancia, el tema se impondrá sobre los obstáculos que han levantado la historia y la cultura

En el medio cubano, de antiguo tan laico, y con una irreligiosidad muy multiplicada por el choque Iglesia-revolución de los primeros anos 60 , la cuestión ha llegado durante un cuarto de siglo por la vía de la solidaridad sostenida de nuestro pueblo con las luchas de liberación latinoamericanas. Camilo Torres, por ejemplo, es para nosotros uno de los héroes populares que representa a todos los caídos luchando por la liberación latinoamericana, cristiano o no, sin exclusiones; la revolución cubana ha reconocido siempre, expresar activamente, el derecho de los cristianos a participar en el proceso de cambios sociales imprescindible en la región. El triunfo sandinista de 1979 fue decisivo para mostrar a todos en América la importancia de la participación cristiana, tema que Fidel Castro habla abordado varias veces con extraordinaria lucidez durante los 20 afios anteriores. La guerra de liberación salvadoreña, el conocimiento creciente de la actividad y el pensamiento cristianos, la relevante participación de religiosos en la reunión sobre la deuda externa de julio de 1985, la entrevista de Frei Betlo a Fidel (Fidel y la religion), tan difundida, son hitos recientes. Cuba actual, con sus inmensos logros y su indeclinable profundización del proceso de liberación, su socialismo marxista leninista y su vocación latinoamericana, participa en condiciones privilegiadas en un encuentro de las raíces y los proyectos de liberación de los pueblos latinoamericanos que tiene necesariamente que incluir a los cristianos.

Este artículo se inscribe, en sus propósitos y limitaciones, en el aspecto del conocimiento, uno más de los que deben concurrir a aquel encuentro, pero en modo alguno un aspecto desdefiable. Deja sin tratar por tanto un tema decisivo: los movimientos populares cristianos, sus formas organizativas y sus acciones, y la participación cristiana en los procesos populares de liberación. Por otra parte, dentro de la producción cristiana latinoamericana escrita no recoge prácticamente nada de la pastoral de cierio número de obispos del continente que han asumido posiciones muy avanzadas junto al pueblo, y cuyo prestigio, autoridad y conducción desempeftan también un importante papel; tampoco analiza los numerosos textos de sacerdotes, hermanas y pastores evangélicos que tienen iguales posiciones. Por último, no tratamos aquí la teología de la liberación elaborada por protestantes, que tiene sin duda importancia desde los inicios de ese movimiento. 
I

Al acercarse a la teologia de la liberación, ${ }^{1}$ lo primero que resalta es que se trata de un cuerpo de pensamiento latinoamericano. La teologfa cristiana es, naturalmente, de origen europeo, y Europa la ha regido casi hasta hoy. La formación misma de los teólogos de la liberación, el patrimonio cultural que aprendieron, la lengua de la teologia, sus temas, sus métodos, tenian que ser, forzosamente, europeos. ${ }^{2} \mathrm{Y}$ sin embargo, el tema, el modo de aproximacion a sus objelos de estudio, la elección misma de esos objetos, las circunstancias practicas, efectivas e intelectuales de producción de la TL, son americanos.

¿Cómo pudo llegarse a esto? La pregunta es necesaria, y no sólo por mélodo: la TL forma parte del tronco de la Iglesia y del cristianismo mundial, de su historia reciente $y$, muy probablemente, de su futuro. Además, la TL y las iglesias no están suspendidas en un espacio que llenan con sus libros, sus pronunciamientos y sus debates, sino que forman parte del complejo desarrollo de las sociedades posterior a la segunda guerra mundial; ámbito histórico que en América se caracteriza, entre otras cosas, por una carrera casi palpable por inclinar la modernización (usemos el término) de las estructuras sociales, y de su comprensión por parte de los implicados, hacia el mantenimiento del régimen existente o hacia su cambio radical, una carrera entre represión, reforma o revolución. La TL no escapa a esos condicionamientos; les debe a ellos mucho de su configuración primera, aunque afirmó su aubonomía, como toda realidad, y actía ella misma como modificadora de circunstancias. El curso actual y las perspectivas de la TL no pueden conocerse sin las instancias de sus condicionamientos.

El equilibrio de fuerzas que sucedió en Europa a las turbulencias de los primeros afios de postguerra se plasmó finalmente en una limitación precisa de las luchas de clases en el seno de cada país, y en una suerte de pacto social que amplió la participación de los sectores nativos de la población en los gajes de un crecimiento económico notable. En el seno de ese capitalismo "maduro" o "tardio" predominaron, al fin, formas democráticas aceptables respecto al discurso clásico. En el terreno religioso, el alejamiento de las práclicas, y aun de las creencias, se acentuó en buena parte de la población europea.

A pesar de la militancia del Papa Pío XI en la guerra fria, en la Iglesia católica se fue abriendo paso una sensibilidad hacia las cuestiones sociales que superó las posiciones de la doctrina social expuesta en las encíclicas de León XII y Pío XI. Por otra parte, el humanismo integral y la nueva cristianidad enunciados por el filósofo Jacques Marilain sirvieron de marco a una consideración cristiana más activa de las realidades del mundo, que concurrió a dar relevancia al papel de los laicos y, por último, a la fundamentación de los partidos socialcristianos contemporáneos. Los movimientos apostólicos renovados, la propuesta de "ver, juzgar y actuar," las experiencias de actividad pastoral con obreros y de "diálogo" con marxistas, van marcando la apertura eclesiástica europea y la intención de "poner al dfa" a "la Iglesia. 
No puede entenderse el extraordinario avance que sobrevino en los aflos 60 sin atender también al intenso trabajo teológico europeo que lo precedió y acompań. ¿Cómo ser cristiano despues de Auschwitz?, se preguntaban, pero no se limitaron a bucear en el analisis de la persona. Teologia de las realidades terrestres, reflexión sobre las dimensiones sociales de los dogmas, teologia de la historia, teologia política, de los laicos, del trabajo, son los apellidos teológicos de una renovación intelectual. El peligro de la desaparición de la fe se les hacía visible, pero sería superficial y muy erróneo ver en su "salida al mundo" un signo oportunista. Se produjo una renovación teológica que ligó el devenir histórico al intento de autocomprenderse, antropologizo sus concepciones de la revelacion, se planté a la Iglesia misma como un lugar teológico y vio la necesidad de romper con la separación Iglesia-mundo y valorizar la actuación humana.

El Papa Juan XXIII (1958-1963) desempentó un papel muy relevante al abrir paso a los cambios en la Iglesia católica. Con gran firmeza y ricas intuiciones superó los horizontes de la propia institución vaticana, exigió a la Iglesia practicar un ecumenismo real, "reconocer los signos de los tiempos," abrirse al mundo contemporáneo y sus problemas, incluidos los de los países subdesartollados, ser "Iglesia de los pobres," reencontrarse y cambiar en medio de "las miserias de la vida social que claman venganza en la presencia de Dios." 3 Al Concilio Vaticano II (octubre de 1962 a diciembre de 1965) que el convoco se le ha considerado el acontecimiento más importante en la vida de la Iglesia católica de los últimos siglos; en todo caso marcó el fin (tardío) de una época en la historia de esa instiución, ${ }^{4}$ y abrió cauces que todavia pugnan por alcanzar una amplitud que el concilio esbozo.

El Papa Pablo VI (1963-1978) conlinuó la obra de Juan XXII, dando fin al concilio, auspiciando la concreción de las ideas principales de éste en documentos rectores y en la creación o impulso de instancias y funciones dentro de la Iglesia que desarrollaran el espiritu del Vaticano II. 5 Ese esplritu era para Pablo VI lo más importante - "debemos pensar de una manera nueva," declaró en enero de 1966 - para continuar la puesta al día y la apertura de la Iglesia a los problemas del mundo de hoy. Una vasta reforma se produjo, y ésta tendió, no sólo a modernizar la Iglesia, sino a permitir que en su seno llegaran a caber actividades como las de los movimientos populares cristianos ${ }^{6}$ y la TL.

Sin embargo, hoy eslá claro para los implicados que la Iglesia del Vaticano II y del postconcilio facilitó, pero no fue la causa o impulso principal de la TL, y aún menos de los movimientos populares cristianos. El Vaticano II fue un evento europeo que miró al llamado tercer mundo desde la Europa capitalista, una región que asimiló la descolonización afroasiática desde su desarrollo y su etapa de auge económico, y la integro en buena medida a relaciones neocoloniales. La óplica mundial del capitalismo europeo pudo ahora integrar desarrollo económico, democracia políica con pluralidad de paruidos e ideologías, y "cooperación para el desarrollo" del tercer mundo, en un marco de crecimiento de la importancia de los organismos y foros intemacionales, y también de contradicciones limiladas de Eu- 
ropa con Estados Unidos. El concilio y el postconcilio caben, a pesar de sus irreductibles especificidades, dentro de los márgenes de la sociedad europea que describimos, y desde ese ángulo son expresión también de una madurez que reconoce la necesidad de reformas.

En su diálogo con la modemidad y con el no creyente, en su planteamiento de la Iglesia como pueblo de Dios y de la autoridad como servicio, el concilio y sus consecuencias no traspasaron la frontera de un reformismo europeo. No hay un movimiento católico que esté inspirando o formando parte de un proceso europeo que vaya más allá, ni hay un florecimiento del cristianismo hoy (la Iglesia pasa por "un tiempo invernal," afirmó poco tiempo antes de morir el famoso té́logo Karl Rahner) en Europa ${ }^{7}$ Se han levantando voces muy críticas entre la jerarquía que atribuyen precisamente a las supuestas desviaciones producidas después del concilio una cosecha de decadencia, descrédito y desunión; esta reacción ha criticado a los téblogos progresistas, presionado a conferencias episcopales e influido en la designación de numerosos obispos y cardenales conservadores. Los resultados del sínodo de diciembre de 1985 muestran más un equilibrio entre impugnadores y defensores que un avance cierto, a 20 afios del concilio.

Era lógico que entre los temas fundamentales propuesios por Juan XXII al concilio fuera el de los pobres el que uvvo menos desarrollo, y que estuvieran ausentes "temas tan latinoamericanos como la profecía, el Jesús liberador, el Dios de la vida, las comunidades de base, la persecución y el martirio." ${ }^{8} \mathrm{El}$ mundo modemo al que exige Gaudiem et Spes asomarse a la Iglesia es el mundo desarrollado, y la receta que propone Populorwn Progressio al subdesarrollo, que tan fuertemente denuncia, es la del desarollismo: se pide al primero justicia y técnica, las cuales, concedidas al segundo (al llamado tercer mundo), eliminarán la pobreza, llevarán al desarrollo y conjurarán el peligro de las revoluciones. No hay que subestimar el lugar que abrieron, en una institución tan vertical y estructurada como la Iglesia católica, las transformaciones y el espírilu conciliares; pero tampoco puede desconocerse el peso actual de sus limitaciones y eventuales retrocesos.

\section{III}

En la América Latina de los afios 60 se estaba produciendo precisamente la bancarrota del desarrollismo, ideal formulado en la coyuntura favorable de finales de los 40. La exportación de productos primarios en condiciones desventajosas de intercambio no pudo ser superada, la industrialización limitada no encontró mercados externos, la mayoría de la población rural permanecí superexplotada y fuera de la vida modema; pronto el imperialismo norteamericano se lanzo al control a fondo de la región mediante la transnacionalización, los mecanismos comerciales y financieros, y mediante un conjunto de medios de extorsión y agresión, la sujeción de las políticas económicas y las actuaciones de los estados a los intereses supremos norteamericanos. La reformulación del pacto neocolonial 
$\rightarrow$ sin olvider la extrema diversidad de situaciones particulares - arrastró a gobiemos populistas, influyó en los procesos de modernización capilalista de muchos palses, mantuvo la despiadada explotación en el campo a pesar de desarrollos capitalistas agrarios, reorientó a las burguesías de cada país en sentidos cada vez más antinacionales y exigió la apelación a regímenes muy represivos.

La acelerada urbanización sin desarrollo nacional consumó la marginalización de enormes sectores urbanos. Las formas tradicionales de vida y los patrones de conducta de muchos millones de personas fueron forzosamente desquiciados, pero en general su pobreza no disminuyo, y su seguridad ante el trabajo, la vivienda, la salud y el futuro personal y familiar no mejoraron sensiblemente. Sus expectarivas aumentaron de manera rápida, y también sus desilusiones: de ambas se Llenó entonces la vida de los pobres, y también la de una parte de los sectores intermedios de las sociedades.

La modernización monstruosa a que ha sido sometida América Latina es el marco inexorable de todo pensamiento que pretenda tener incidencia social en ella, y de todo proyecto de cambio. En esta región se han sumado como en ninguna otra la complejidad de contradicciones del mundo actual, y su conocimiento es una brijula imprescindible.

El mismo régimen político capitalista está sometido a tensiones extremas. Las ideas democráticas burguesas, tan antiguas en el seno de las minorías, van encontrando campo y necesidad de aplicación masivas, porque en ellas parecen confluir intereses nacionales, aspiraciones populares y la propia creciente influencia cultural norteamericana. A la vez, son superadas por la representación de poderes mucho más efectivamente populares, e incluso socialistas, cuya realided respectiva en Nicaragua y Cuba está a la vista. Sin embargo, la modernización con superexplotación, neocolonizada, excluyente, exige un patrón represivo de Estado y de relaciones entre clases que lleva una y otra vez a la dictadura y a matanzas salvajes y organizadas, incluso en los parses en donde se hablan obtenido crecimientos económicos fuertes, y más o menos sostenidos, y, donde se hablan desarrollado cierto número de instituciones democráticas.

El reformismo resultaba (y resulta) ya imprescindible en el continente para mantener el capitalismo, pero a sus modelos les falta una y otra vez lo indispensable: el mínimo de redistribución de riqueza y servicios sociales que sea efectivo; un grado de organización con liberlades polílicas y de la sociedad civil que garantice el consenso, el avance progresivo del régimen y los anticuerpos de la revolución.

Para la mayoría de la población latinoamericana en los años 60 la pertenencia a partidos políticos era nula o ineficaz en cuanto a promoción de un cambio social efectivo; lo mismo puede decirse de los sindicatos y demás organizaciones populares. No se debe creer, sin embargo, que no existlan rebeldias activas o que éstas no eran numerosas: la agitación, protestas y revueltas populares por de- 
mandas inmediatas y por causas antidictatoriales enfrentaron a todo este proceso como pudieron, y constituyen una de las condicionantes fundamentales que hay que tener en cuenta. Y en la conciencia social de la gran masa se fueron abriendo paso representaciones más naturales del mundo, de la mano de la urbanización. las relaciones mercantiles, la expansión de las matrículas escolares, la extensión del alcance y difusión de los medios masivos de comunicación, el mayor conocimiento de los sucesos del mundo. Las realidades políticas y sociales, las ideas acerca de ellas, comenzaron a mostrar sus propios contornos.

El triunfo de la revolución cubana fue la primera gran irrupción de los pobres en la historia en este continente. Sus rápidos avances en el proceso de liberación, su enfrentamiento vertical e intransigente con el imperialismo norteamericano, y su intermacionalismo, se convirtieron en un polo de gran atracción en el escenario americano. Cuba demostró con fuerza dramálica que la miseria, la impotencia y la desgracia del individuo respecto a la sociedad en que vive no proceden de su destino ni de su naturaleza individual; que es posible para los pobres vencer el aparato represivo, tomar el poder y redistribuir las riquezas sociales; que es posible emprender el camino de la humanización de la existencia, la promoción de las capacidades y el desarrollo para todos en una sociedad americana. Y todo en un pequeflo país en la boca del Golfo de México, al norte del Caribe, a los pies mismos de Estados Unidos.

El ejemplo cubano animó extraordinariamente a las rebeldías latinoamericanas, contribuyendo a darles confianza en sus fuerzas, certeza en la posibilidad de triunfar, radicalización de los medios y de los objetivos de la lucha, materialización en América de las ideas de la liberación y del socialismo. Pero no solo afectó al campo popular. La polltica norteamericana hacia América Latina se multiplico en su actividad y reconí toda la gama del intervencionismo, a la vez que promovía o ayudaba a crear alternativas reformistas. Las burguesías y todos los intereses opuestos a los cambios profundos del continente anatematizaron de todas las formas posibles a la revolución cubana La consigna central del gobierno democristiano chileno de 1964-1970 fue "revolución en libertad."

Esta era la siuuación, en térninos generales, cuando la Iglesia latinoamericana recibió el impacto del Concilio Vaticano II. Los propios té́logos latinoamericanos han expuesto cómo sucedio, y han valorado críticamente los significados y los aportes. 9 Sólo quiero destacar aqul algo que es obvio en las primeras obras de la TL: la negación radical del orden social injusto vigente en el continente, la perspectiva teórica desde Latinoamérica, que asume en general la llamada teoría de la dependencia para explicar aquel orden social, la crítica al desarrollismo y el reclamo de un proceso liberador, la exaltación de la praxis como punto de partida del trabajo teológico y de la actitud cristiana, la exigencia a la Iglesia de comprometerse en la lucha de los pobres, un lenguaje independiente que puntualiza la diferencia de temas, enfoque y actitud de la nueva teología, aunque siempre reconociéndose dentro del universo teológico y eclesial. 
Esto es, en su origen la TL tiene una coyuntura propicia en el gran movimiento reformador europeo epitomizado en el Vaticano II, pero su formulación primera es producto de una aprehensión profunda y radical de la situación concreta de América Latina. Ha resultado sorprendente para muchos entre los no creyentes el radical discurso de la TL (y seguramente también para los cristianos conservadores o tradicionales). Cuando revisamos sus escritos no encontramos referencias suficientes a un pensamiento teológico latinoamericano avanzado anterior a ellos, del cual la TL fuera continuadora. Los creadores de la TL son, por otra parte, hombres formados en los centros del pensamiento teológico de Europa, por tanto "teólogos de verdad," con conocimientos profesionales y capacidades que nadie dentro de la Iglesia les discute. Se puede inferir de todo esto que la formulación primera de la TL es el resultado feliz de un instrumento intelectual que marcha hacia el límite fijado a sus posibilidades (europeo, reformista), pero que en manos de quienes están inmersos en una sociedad de urgencias y estructuras diferentes, para ser útil a sus praxis tiene que trascender aquellos límiles y producir planteamientos revolucionarios.

Si bien esto es cierto, resulta, sin embargo, insuliciente. La Iglesia latinoamericana misma, muchas de sus prácticas y actitudes, desempefiaron un papel importante en el surgimiento de la TL. El desarrollo de movimientos cristianos a partir de la Acción Católica en los medios estudiantiles, obreros, campesinos; las escuelas radiofónicas y las actividades de educación popular, la aparición de las primeras comunidades de base, son manifestaciones organizadas de una voluntad de participación. La orientación vaticana y los organismos eclesiales que tienen su centro en Europa está presente en la mayoría de ellas, así en la creación de órganos como el CELAM y la Conferencia Latinoamericana de Religiosos (CLAR), como en la creación de partidos democristianos en varios países para movilizar la actuación "en cristiano" hacia el apoyo político de un capilalismo renovado o reformado. Pero los resultados prácticos desbordaron parcialmente los proyectos originales.

Frente a los violentos y rápidos avances de las ideas y las luchas de liberación nacional y socialista, por una parte, y de la modernización capitalista neocolonial por otra, en nuestro continente resultaban insulicientes los canales de organización y de conciencia políicos. Se abrió un ciclo de luchas populares de todos modos, con su entorno de concientización, de agitaciones e inquietudes sociales correspondiente, con la impaciencia que caracteriza a las necesidades sociales ciertas. Es aqui que la conciencia y las formas organizativas cristianas se radicalizaron, ocupando parte del espacio político por llenar. Esta comprobación no debe llevar a lamentaciones por demás inútiles: la conciencia social es una, son los individuos los que entran o no en las luchas que cambiarán las sociedades y los cambiarán a la vez a ellos mismos. ${ }^{10}$

No fue, no podía ser, homogéneo ese movimiento, hijo de la diversidad de clases sociales, de etnias y de culturas regionales y nacionales donde está enraizado el cristianismo latinoamericano; referido a la institución eclesíśstica, con 
sus niveles de autoridad y autoritarismo, sus criterios pastorales, su conservadurismo y sus prejuicios políticos. Sus manifeslaciones son de una gran diversidad, ${ }^{11}$ pero en conjunto cumplen un itinerario que deja establecido un papel para la Iglesia (¿más de uno?) en la vida social y política latinoamericana actual, y la actividad de los movimientos populares cristianos como una parte importantísima de esa Iglesia. Dejando provisionalmente a un lado la cuestión teórica de la función social de la religión en el mundo contemporáneo, la constatación práctica que puede hacerse en América Latina es que - sin perder sus funciones de legitimación y de justificación dentro del bloque dominante en las sociedades capitalistas - la fe religiosa asume también formas organizativas y de conciencia diferentes e incluso opuestas tolalmente a la dominación capitalista.

La segunda cuestión, intimamente ligada a la primera, es que numerosos cristianos - y entre ellos los que hacen TL - sostienen que aquella conciencia y organización opuestas a la dominación son la respuesta cristiana obligada al momento historico que vivimos, la praxis que identifica lo que es ser Iglesia hoy, que dimana de ella, o la base de su reinvención, lo que permite representarse el reino, y comenzar a construirlo, interpretar la Escritura y la tradición, asumir a Cristo y su mensaje, obtener la salvación (ante todo, identificarla), prestar servicio como misión del cristiano y de la Iglesia.

En resumen, existe todo un conjunto de fe, de representaciones, de pensamiento y trabajo teológico, que se reclama productor de pensamiento y actitud liberadores, y que reclama para su actividad el objetivo práctico de concurrir a la liberación de los hombres en Latinoamérica. Que sean minoría numérica respecto a la totalidad de los creyentes e instituciones eclesiásticas, no es más que un dato. Que conciban la liberación al interior de sus propias ideas, convicciones y fe religiosas es algo cuya importancia dificilmente puede ser exagerada.

Ya en la reunión de teólogos latinoamericanos celebrada en Petrópolis (Brasil) en marzo de 1964, el peruano Gustavo Gutiérrez planteó que la teología debla ser una reflexión crítica sobre la praxis. En los años siguientes continuó, desde esa posición, tratando el tema de la pobreza, en lo que él mismo llamó "hacia una teologfa de la liberación." A inicios de la década se había reclamado en medios cristianos brasileffos la necesidad de diálogo con los marxistas; "en Brasil, la izquierda católica produjo entre 1959-64 una serie de textos básicos sobre la necesidad de un ideal histórico cristiano, ligado a una acción popular..."12 Una sucesión de encuentros teológicos entre 1964 y $1971^{13}$ sirvió para socializar los puntos de vista y los temas, para autoidentificarse y relacionarse, en lo que ya todos convinieron en llamar teología de la liberación. En medio de ese tiempo ocurrí en Medellín, la Segunda Conferencia General del Episcopado Latinoamericano (CELAM), cuyo tema era la transformación de América Latina a la luz del Vaticano II.

Medellín resume el alcance de la puesta al dia de la Iglesia institución en América Latina. Reconoció que la pobreza predominante era fruto de las relaciones 
de poder, económicas y sociales vigentes, denunció la pobreza "y el pecado que la engendra;" califico de "violencia institucionalizada" la situación de injusticia prevaleciente "en muchas partes" del continente, y ante la "tentación de la violencia" que aquella engendra se pronunció por la paz, pero una paz condicionada por la justicia. Se dirigí abiertamente a "todos los hombres que en este continente tienen hambre y sed de justicia." Postulo el amor a los hermanos y a Cristo como gran fuerza liberadora y planté que donde no existe paz social y st injustas desigualdades, "hay un rechazo del Senor mismo." Expone la situación concreta de América Latina y su momento historico14 y pide mostrar "el rostro de una Iglesia auténticamente pobre, misionera y pascual, desligada de todo poder temporal y audazmente comprometida en la liberación de todo el hombre y de todos los hombres."

Medellin fue un momento en que había en América una gran conciencia de que tenfan que sobrevenir cambios profundos; para muchos las revoluciones parecian inminentes o ya comenzadas; el despertar de Iglesia coincidió con él.15 Es muy importante tener en cuenta los cambios que afectaron aquella atmósfera después de los primeros aftos 70 . La Iglesia institucional no volvió a alcanzar un momento como el de Medellín, 16 el propio CELAM perdió paulatinamente su carácter impulsor hasta convertirse en lo que es hoy, y la tercera conferencia (Puebla, 1979) fue precedida de una lucha ardua entre los que querian plasmar una involución y condenar incluso a la $T L, y$ los que reafirmaban la corriente renovadora y pretendían profundizarla. Los tex los de Puebla y la actividad paralela de teologos de la TL que fueron acompaftando a obispos y cardenales progresistas, ya que los organizadores no les habian dado lugar en los equipos de expertos, ${ }^{17}$ testimonian ese enfrentamiento.

Puebla recogió planteamientos esenciales de Medellin, precisó y aún avanzó en algunos puntos, y también expresó el impacto de la ofensiva conservadora que condicionaba la aceptación de la TL a definiciones muy restrictivas de la misma Dado el verticalismo de la Iglesia institucional, su unidad y lo expresado en sus documentos tienen una enorme importancia, de modo que las citas y comentarios del Vaticano II, Medellín, Puebla, y de las iniciativas de Pablo VI (como el sinodo vaticano de 1971 o la Octogesima Adveniens) adquirieron un gran peso en los debates. Ellos son un terreno ganado ya, que favorece la actividad de la TL y de los movimientos populares cristianos, a pesar de la revisión de tendencia conservadora realizada en la Iglesia en los úlimos años.

Ya en 1962 Juan Luis Segundo habia esbozado el problema de las contradicciones entre la estructura de la Iglesia y su misión. ${ }^{18}$ Casi 20 antos después, en Iglesia: carisma y poder, Leonardo Boff desarrolló a fondo la cuestión; 19 prácticamente todos los teólogos de la liberación han tratado el tema a lo largo de esos aftos, y hasta hoy. La incorporación del análisis de la propia Iglesia con el auxilio de las ciencias sociales es otra caracteristica del pensamiento teológico de la TL. 
En el terreno práctico eclesial, el camino andado en los 60 y en los 70 , am desde puntos de partida desarrollistas y modernizantes, dernocristianos y socialcristianos, de asistencialismo social o externa comunicación con "el pobre,"20 fomb en miles de cristianos latinoamericanos una nueva conciencia, receptiva y activa ante las luchas y demandas populares, y produjo un cambio en su autoidentificación como cristianos y en su idea de comunidad e Iglesia cristianas. Esto se multiplicó en formas organizativas, en publicaciones, en divulgación y educación popular. El compromiso activo devino militancia en muchos, en organizaciones cristianas ligadas al movimiento popular, y directamente en organizaciones populares revolucionarias también. La represión brutal de estas dos décadas cré también un extenso martirologio crisliano, sangre vertida que a la vez forma parte inseparable del acervo popular revolucionario latinoamericano.

Una parte del clero asumió también la práctica más allá del terreno modernizante. La pastoral entre la gente más humilde de la ciudad y del campo, el compromiso concretado, nutrieron de vivencias y experiencias a muchos. Organizaciones o grupos sacerdotales contribuyeron a hacer más efectiva la presencia e influencia del clero avanzado, y a esto se unió la actitud de respaldo, y en varios casos de conducción, de obispos esclarecidos de diversos paises. ${ }^{21}$ El autoritarismo jerárquico y el paternalismo clerical han perdido terreno como resultado de la actividad de esas vanguardias de la Iglesia. Y ya son numerosos los sacerdotes -y algunos obispos - que han pagado con la vida su amor práctico al pobre 0 su entrega militante a la causa popular.

\section{IV}

La autovaloración y la metodologí de la TL nos ha hecho asomarnos a sus contenidos ya en el curso del análisis de sus condicionamientos eclesiales y sociales. Ahora trataremos de sintetizar una exposición de sus temas y contenidos fundamentales, no con la pretensión de exponerlos totalmente -mucho menos de presentar de manera exhaustiva la TL, lo cual está fuera de nuestras posibilidades-, sino de suministrar al lector no iniciado elementos indispensables y que lo animen a leer a los téologos mismos, y con el fin de tratar la situación actual y adelantar algunos criterios nuestros.

La cuestión misma de quién hace TL evidencia que para estos té́logos se trata de una nueva manera de hacer teologia. Ellos parten de que la reflexión teológica se encuentra en la masa de los creyentes, en la inteligencia de su fe, en la experiencia espiritual de Dios como el Dios de los pobres y del pobre como lugar del encuentro con Dios, en la confrontación de la fe cristiana y la situación de opresión, en la práclica histórica de la liberación del pueblo pobre y creyente latinoamericano. 22 Por tanto, la TL no se inicia con el teólogo, ni se reduce a su actividad "profesional." Richard distingue tres formas de TL: espiritual en la práctica de la liberación del pueblo, orgánica en las comunidades eclesiales de base (CEB) y teología profesional. Los Boff las clasifican como popular, pastoral y 
profesional, de acuerdo a características que enumera, referidas a su grado de elaboración, relaciones con la práctica, lógica, método, lugares de aplicación, productores y productos. Gutiérrez, que trata el tema a lo largo de toda su obra, la llama "una reflexión que nace desde el reverso de la historia"

La función del teólogo adquiere una nueva importancia desde esa perspectiva, a la vez que se reduce bruscamente la pretensión de dominio desde la función intelectual que caracterizó a la teología. Forma parte de la teología explicar el lugar del télogo 23 y los condicionantes históricos - por tanto cambiantes- de la teologia Se comienza asi a desplegar un problema que en el caso de las ciencias sociales ha sido consecuencia de comprender la historización de lo intemo de la producción misma de conocimientos, y el modo como los condicionamientos sociales intervienen en el campo cientffico social; un problema complejo en sl mismo y en sus consecuencias practicas, que tiene larga historia en el caso del marxismo.

Los pobres, la liberación, la unidad de la historia, la espiritualidad, la relación entre fe y política, el amor y la violencia, son temas que se presentan como inevitables ante la TL. Los teólogos los asumen y los desarrollan, los trabajan teológicamente; los resultados varían de acuerdo a condicionamientos específicos y a características individuales. Ya se puede hablar de una trayectoria en el tiempo, con algunos indicios de cambios, y también hay diferencias que algunos llegan a agrupar en tendencias. Pero el fenómeno tiene suficiente unicidad para poder referirse a sus temas, a sus posiciones y a su manera de hacer teología. Tiene también, y esto es de la mayor importancia, la interpretación o percepción que hacen de la TL los medios sociales y las instituciones implicadas cn el cristianismo: que se corresponda o no totalmente con sus contenidos teóricos puede ser materia de malos entendidos y de aclaraciones, pero indican un sentido general de la TL y unas necesidades sociales a las cuales también se debe la TL, y ambos forman parte de su realidad.

¿Cómo ser cristiano en un mundo de miserables? ¿Con qué lenguaje decir a los que no son considerados personas que son hijas e hijos de Dios? Preguntas como éstas se hacen los teólogos a partir de la constatación de la situación de miseria, de injusticia y explotación en que viven las mayorias latinoamericanas. La mediación socioanalítica ${ }^{24}$ de la TL se propone conocer las condiciones reales en que se encuentra el oprimido y sus causas. Este es el campo donde es más general y aceptada la utilización del marxismo por la TL; más diferenciada es la aceptación en lo que se refiere a las luchas de clases de los oprimidos. Para la TL el pobre es explotado económicamente, oprimido, marginado, discriminado racial, sexual o culuralmente.

La pobreza no es más "una fatalidad" ni algo que hay que aceptar y ante lo cual hay que resignarse. La pobreza material es un estado escandaloso, condenado en las Escrituras, la tradición cristiana e incluso en parte del magisterio eclesiástico. La pobreza espiritual del cristiano no es simplemente desprenderse de riquezas, es tener una total disponibilidad ante Dios; es esperar y acoger a Dios. Digitalizado por Biblioteca "P. Florentino Idoate, S.J."

Universidad Centroamericana "José Simeón Cañas" 
Gutiérrez plantea una síntesis: "la pobreza cristiana, expresión de amor, es solidaria con los pobres y es prolesta contra la pobreza." 25 Seguin los Boff, esta solidaridad con los pobres tiene raíces propias, inherentes a la fe cristiana: teológica (desde el Dios bfblico), cristológica, escatológica (como en el juicio final seguin el evangelio de mateo), apostólica (de la Iglesia primitiva) y eclesiológica (la opción preferencial por los pobres, proclamada en Medellín y ratificada en Puebla). ${ }^{26}$

La cuestión de los pobres en la TL no se limita al campo de lo social y económico; se sitúa al nivel de la fe. Esto la diferencia analíticamente de las ciencias sociales, aunque las utilice. Bien entendida, la cuestión de la fe nos permite no reducir la posición de la TL a su dimensión política, ni a una interpretación de la realidad a partir de las ciencias sociales. "La función de la TL no ha sido, por lo tanto, la de introducir la política en la teología, sino la de introducir la teología en la experiencia de Dios que el pueblo pobre y creyente realiza en su práctica política de liberación," ha escrito Pablo Richard. ${ }^{27}$ No es hacer ciencia o política, pero sí ayudar a que el compromiso liberador de los cristianos sea más radical y más lúcido. 28

Situarse, pues, en la perspectiva del reino de Dios es participar de la lucha por la liberación de los hombres oprimidos por otros hombres. La noción de espiritualidad ("seguimiento de Cristo," serfa su sentido estricto) para la TL exige en el cristiano una conversión al prójimo -explicitado este en el hombre oprimido con los atributos que hemos descrito-, significando con ello una transformación radical de cada uno, encontrar a Cristo en el proceso de liberación y hacer de esta actitud algo que incluya toda la actividad vital del individuo, que dé significado como totalidad a cada detalle y aspecto de su vida.

Esta espiritualidad se realiza dentro de una comunidad, "es una aventura colectiva." Y es un proceso de conversión y de aprendizaje en la praxis que no termina, que reclama el curso de la vida de los cristianos. Totalidad, comunidad, búsqueda, formación y dedicación a lo largo de la vida; en la riqueza teológica de este concepto de espiritualidad está también la posibilidad de establecer una insoslayable y fecunda confrontación con las ideas revolucionarias de cambio total de sf mismo.

Partiendo de la gratuidad del amor de Dios, expresada en el lenguaje míslico, en la contemplación, la TL busca en el lenguaje profético la denuncia de la situación de injusticia y despojo en que viven los pobres. De la unión de ambos sale la teología, situada en la historia y buscando eficiencia para la praxis que es necesaria en esa situación histórica. Se reivindica así la oración, se vuelve a interpretar al Nuevo Testatamento y el conjunto de los libros de la Biblia, ${ }^{29}$ y se van desarrollando los temas de una cristología y de una eclesiología de la TL. AJ nivel pastoral y en la actividad cristiana influida por las nuevas ideas se extiende ahora la relectura de la Biblia que encuentra un forlalecimiento de la fe y de la convicción en que el camino del cristiano es el de esperar y luchar por la liberación. ${ }^{30}$ 
El concepto de liberación de la TL recorre, como es natral, toda su producción; sin embargo, más que definido suele ser explicitado como práctica, como necesidad, como proceso histórico, puesto en relación con el pobre, el oprimido, el cristiano, con Cristo, con Dios y con otros conceptos manejados por la teologia. No obstante, los tres niveles de significación del término que expone Gutiérrez en 1971 son generalmente aceptados: a) "liberación expresa, en primer lugar, las aspiraciones de las clases sociales y pueblos oprimidos, y subraya el aspecto conflictual del proceso económico, social y político que los opone a las clases opresoras y pueblos opulentos;" b) "concebir la historia como un proceso de liberación del hombre, en el que éste va asumiendo conscientemente su propio destino, coloca en un contexto dinámico y ensancha el horizonte de los cambios sociales que se desean. Sibuados en esta perspectiva aparecen como una exigencia del despliegue de todas las dimensiones del hombre;" c) "... hablar de liberación permile otro tipo de aproximación que nos conduce a las fuentes bíblicas que inspiran la presencia y el actuar del hombre en la historia [...] Cristo salvador libera al hombre del pecado, raíz última de tods ruptura de amistad, de toda injusticia y opresión, y lo hace auténticamente libre, es decir, vivir en comunión con él, fundamento de toda fratemidad humana. ${ }^{31}$

Esos tres niveles pertenecen a "un proceso único y complejo que encuentra su sentido profundo y su plena realización en la obra salvadora de Cristo." 32 Salvación y liberación quedan intimamente relacionadas, y ambas nociones están enriquecidas de un modo que influye poderosamente en la rellexión teologica y en la manera de ser cristiano. El sistema mismo de creencias, representaciones y rituales religiosos, las instituciones eclesiásticas, son miradas a la luz de una fe que se siente histórica, humana, activa y crítica. Las formas concretas -y los conceptos abstractos-que habla adoptado la modernización de la relación Iglesiamundo corren el riesgo de ser arrasadas por esta concepción realmente integradora del terreno de la necesidad más sentida por los pueblos latincamericanos y el terreno de las dimensiones más hondas del cristianismo como fe, conciencia popular y proyecto.

Es comprensible que tal idea de liberación se considere extremadamente peligrosa por los beneficiarios y los defensores del orden y el sistema de explotación en América Latina, y por los burgueses y el gobierno de Estados Unidos. Las profundas exigencias que envuelve el concepto de liberación están articuladas por una espiritualidad determinada: en la medida en que se es cristiano y comunidad cristiana se pretende practicar el proceso liberador, ese proceso a su vez será el que los constituya como cristianos de hoy y de mafiana.

No se trata, por tanto, de la elección entre ser cristiano o ser revolucionario radical en el curso de la lucha social, o de abandonar el sacerdocio o las creencias religiosas como parte de un desarollo personal. Se trata de una reafirmación de la fe y de un replanteamiento de qué es ser Iglesia y cómo serlo, que integra como algo indispensable la praxis en defensa de los oprimidos, de los derechos humanos y de los cambios profundos de las sociedades latinoamericanas. ${ }^{33}$ 
La historia es una dimensión esencial en la TL. La afirmación de la Iglesia contemporánes de que no hay "dos historias," sino una historia humana única, es profundizada por la TL, como ya se ha visto en citas y comentarios anteriores. Partir de la praxis historicamente condicionada por los hombres es relacionar la fe y la teologla con el movimiento histórico de la humanidad. Varias consecuencias importantes tiene esa posición. Tanto el compromiso del cristiano y la comunidad como la reflexión que los acompaña se renuevan y adquieren contenidos nuevos en las sucesivas etapas históricas. La "verdad" dogmática abstraída del tiempo se hace inaceptable, ${ }^{34}$ y se da paso a planteamientos tan ricos como el de que la verdad evangelica es una verdad que se hace.

La reflexión misma sobre Dios busca, entonces, apoyo en el conocimiento profundo del tiempo en que se vive. Pero no es sólo eso: la interpretación de la salvación, del pecado, de la evangelización, elc., se enriquecen y se precisan, 35 sin dejar de ser materia teológica. Por otra parte, se abre el camino para una comprensión de la historia, de la religión y la Iglesia de los papeles sociales desempeftados por ellas a lo largo de la historia ${ }^{36} \mathrm{Y}$ por último, pero muy importante, se emprende un trabajo de relectura de las Escrituras a la luz de esas concepciones, fundando asf una verdadera cristologia de la TL; se sitúa en sus lugares y condicionamientos históricos a la tradición y el magisterio eclesiástico, y se avanza en el terreno eclesiológico.

La utilización de los resultados obtenidos por las ciencias sociales, y en alguna medida sus métodos, como auxiliares del trabajo teológico, deviene imprescindible, dado el propio núcleo central de la TL y su metodología. La nueva teologia se fortalece con esa apropiación, porque la ayuda a leer los hechos historicos en función profética. Relacionarse con las ciencias de modo indisoluble a la relación entre fe y sociedad no es poco; buscar los signos que guien la praxis hacia un fuburo esbozable y que permilan organizar la esperanza es todavla mucho más.

Al revisar los textos de los teólogos de la liberación que han estado a mi alcance, y entre ellos algunos más recientes que se han visto forzados a volver sobre el tema, ${ }^{37}$ no encuentro razones para la tan reiterada crítica eclesiástica a la TL por su utilización de las ciencias sociales; esa crftica piensa que por ello la TL tiene el peligro de caer en graves desviaciones. Si algo puede advertirse es que los teslogos de la liberación trabajan desde la teologia con las ciencias sociales; la modemización bien entendida de Iglesia debera más bien aplaudir los logros que en la asimilación de esos instrumentos del conocimiento social ha hecho la IL.

Parece haber un fuerte componente ideológico en esas críticas, sin olvidamos de la fuerza que todavia tienen el conservadurismo y el tradicionalismo en los medios cristianos (cuya historia, por cierto, puede conocerse mejor y puede tender a superarse con ayuda de la TL). Más allá de una preocupación excesiva porque el proceso de secularización que ha caracterizado a las sociedades cristianas en los últimos siglos se vuelva una corriente peligrosa, "secularista," dentro de la 
Iglesia (el hombre ya no sería la imagen de Dios, sino al revés, lo divino sería símbolo de lo humano, etc.), aparece la acusación de que la TL introduce el marxismo en el pensamiento y la práctica religiosos, ${ }^{38}$ peligrosa introducción que lleva sin remedio hacia el ateísmo.

¿Por qué se pretende sacrificar uno de los aspectos más importantes de la "puesta al dia" preconizada desde Vaticano II, el abrirse a un conocimiento profundo y consciente de las sociedades, al acusar a "algunas TL" de introducir "la ideologian y el marxismo? Los teólogos de la liberación han apelado al buen sentido de sus criticos cuando anotan un simple hecho muy visible: ninguno de ellos se ha vuelto ateo en estos 20 afios. Derivaciones práclicas de participación de la fe, el pensamiento y las organizaciones religiosas en la actividad consciente de millones de latinoamericanos que necesitan con urgencia conocer su mundo y cambiarlo, son también consecuencias potenciales ostensibles de positivo valor para la religión y la Iglesia. Hay una contradicción aparente entre la modemización y la Iglesia y su doctrina social y esas críticas a la TL.

Volvamos a los contenidos de la TL. La cristologra desempeffa en ella un papel central; 39 no pretendemos exponer sus aportes aqui. Anotemos, sin embargo, algunos conceptos y planteamientos que nos ilustren sus posiciones. 40 Ante todo se reivindica la obligación del cristiano de hablar a partir de Jesús y no sobre él, "como quien está tocado por la significación de su realidad." Este seguimiento implica al análisis de su legado, desde una praxis concreta e histórica latinoamericana. Se considera a Jesús como el máximo exponente de Dios y el Nuevo Testamento como la elaboración que de aquella expresión hicieron las primitivas comunidades cristianas en sus circunstancias (fines de siglo I). El Jesús histórico es privilegiado, ${ }^{41}$ y se estudia su existencia y su praxis histórica; los evangelios mismos son entendidos como la interpretación que desde su praxis hicieron los primeros cristianos del mensaje de Jesús. Y toda la cristología posterior es puesta en relación con sus condiciones de producción.

La predicación y la acción de Jesús están centradas en el reino de Dios. El reino no está solamente en el futuro, está también entre nosotros; no se origina en este mundo, aunque se comienza a realizar en el. El reino es la liberación total e integral. El pecado social y personal es la negación del reino de Dios y debe ser erradicado, no meramente perdonado. La predicación de la buena nueva se hace en un mundo regido por el pecado; la conversión que para el cristiano implica acceder al reino que Dios ofrece a todos es un proceso caracterizado sobre todo por un cambio de actitudes respecto a todas las relaciones sociales, personales y religiosas. El cambio de actitudes debe ir acompafiado de una práctica consecuente.

La divinidad de Jesús está fuera de duda, como lo está la disyuntiva entre fe e incredulidad. ${ }^{42} \mathrm{La}$ comprensión de su práctica histórica de liberación debe partir de la idea del reino que predicó y que se acerca como liberación. Jesús vivió entre los más pobres y oprimidos. El mismo fue pobre. Escogió a sus disclpulos entre los 
más "débiles y necios," para anunciar y servir al reino. El reino "... ya se concretiza en la práctica de Jesús [...] su anuncio liberador ya se historiza entre los oprimidos, interlocutores privilegiados de su predicación y primeros beneficiarios de su práctica ${ }^{\text {43 }}$ El amor universal y la preferencia por los pobres caracterizan el anuncio que hace del reino; y su persecución y muerte son consecuencia de la negación de su mensaje por parte de los opresores y privilegiados de la sociedad en que vivi6. ${ }^{44}$ Jesús presenta a Dios el dolor y el abandono en que han vivido los oprimidos a lo largo de la historia. Su fe, centrada en la fidelidad a Dios, y su misión de instaurar el reino, Jesús las fue viviendo en su hisworia concreta como búsqueda 45

Jesús es consciente de que su mensaje de amor chocará con el pecado social y de que las estructuras a las que este responde deben ser transformadas. "Jesús mostro con su ejemplo que puede haber compatibilidad entre el amor a las personas y la oposición a sus actitudes." 46 El seguimiento de Cristo se hace a través del servicio al reino de liberación y de la lucha contra el pecado, el cual niega a Dios y al reino. El don liberador de Cristo permile entrar en comunión con Dios y con todos los hombres, define los actos y la vida cristiana en un proceso que se da históricamente en la liberación, pero que no se agota en ese proceso, es su anuncio.

En la cristología de la TL se encuentran muchas de las páginas más inspiradas que hemos leído de esa corriente de pensamiento. El punto de partida y el método de la TL producen una interpretación de las Escriuras (hermenéutica) y un discurso teológico plenamente referido a los hombres concretos, reales y sus praxis históricas de liberación. No se trata de los hombres en general, sino de los oprimidos reales, de los explotados que han existido y existen; sus luchas son el teatro del proceso histórico de liberación. ${ }^{47} \mathrm{El}$ mensaje se dirige a los pobres. La pobreza es sinónimo de disponibilidad y condición del seguimiento de Cristo; la lucha lleva a la liberación y el proceso nunca terminado de aquella formará hombres nuevos. Las bienaventuranzas se llenan de sentido y promueven la fe y las convicciones; la reformulación de la utopia permite prefigurar melas y vivir ideales en medio de las terribles condiciones del continente.

Ya hemos visto antes cómo nuevas ideas y prácticas cristianas, expresadas en la TL y en los movimienlos populares cristianos exigen profundización y replanteamientos de las concepciones que se tienen sobre la Iglesia. La modernización conciliar y postconciliar fue decisiva para todo el catolicismo, pero es obvio que las necesidades latinoamericanas van más allá del campo de esas reformas. La eclesiología de la TL tenía que ser terreno recorrido desde los inicios de la Iglesia. Ha sido teatro de muy duras polémicas, y no por afán de confrontación, sino porque en América Latina, las condiciones sociales y el nivel de las luchas, la toma de conciencia cristiana y las formas de organización y de pensamiento desbordan las esctructuras, funciones y estilo de la Iglesia institucional. 
La TL reclama la formación y desarrollo de una nueva conciencia eclesial y la redefinición de la tarea de la Iglesia en nuestro mundo. El punto de partida conciliar de la Iglesia como pueblo de Dios ante todo, que declarativamente inplica un lugar secundario para la jerarquía, se toma aquí en sentido estricto: las comunidades cristianas y la actividad liberadora del cristiano son lo primordial. La actividad cristiana, condicionada a su vez por la actividad concreta e histórica del mundo donde ella está inmersa, será decisiva para que la Iglesia encuentre su misión en América, la cumpla y se fortalezca y se desarrolle a la vez como tal Iglesia.

Dado el carácter de la TL, la cuestión pastoral es central en su eclesiologia, pero analizada a la luz de los logros y posiciones a que hemos hecho referencia aquí. Identificada la Iglesia institución en su proceso histórico y en sus relaciones con la fe del pueblo y con las esctructuras sociales que se han sucedido en el continente, ${ }^{48}$ se miden su peso y sus condicionamienlos en las sociedades actuales, para entender e impulsar sus acciones posibles. ${ }^{49} \mathrm{Se}$ trata el problema de las relaciones y la posible articulación de la Iglesia con otras fuerzas sociales que buscan cambios cualitativos en el sentido de la liberación, reivindicando siempre la perspectiva específica donde ella (liberación integral, reino de Dios) se inscribe. La cuestión de la participación en política es obligada. Se parte del magisterio eclesí́stico, especialmente de Pablo VI y de Puebla, para insistir en los deberes de los cristianos respecto a la concreción del compromiso con los pobres y oprimidos; las formas y los IImites de participación de las jerarquías y los laicos buscan poner en concordancia la interpretación de aquellos textos con las realidades y las urgencias que se presentan ante los religiosos y laicos en la actualidad.

El potencial evangelizador de los pobres ${ }^{50}$ se vuelve un punto central. Si la TL busca ser, ante todo "la interpretación de la fe que viene de los pobres, ${ }^{\mathrm{n}}{ }^{\mathrm{l}}$ la Iglesia debe nacer de la fe del pueblo para poder presentarse como seffal e instrumento de liberación. ${ }^{52} \mathrm{La}$ dimensión institucional de la Iglesia en las sociedades de clase ha estado, sin embargo, afectada por ese carácter clasista Más que enumerar los hechos que ilustran el desvio de la institución de su misión respecto a la fe y al mensaje cristiano, la TL analiza los procesos y las estructuras de poder, creadas al cabo de ellos, la necesidad de cambios profundos que revolucionarán a la Iglesia institucional y a la fuerza motriz que será para ellos la praxis cristiana de liberación. $53 \mathrm{La}$ TL ha aportado al conocimiento de las formas de poder y a su ejercicio en la Iglesia institucional el uso de las ciencias sociales 一mediación socio-analítico-religiosa la ha llamado L. Boff.

Es también en este terreno que la TL retoma y desarrolla la cuestión de las relaciones entre Jesús, su predicación y la Iglesia. La comprensión histórica de la Iglesia, y sobre todo el lugar central que ocupa la cristologia, hacen que la TL fundamente desde el Nuevo Testamento el papel deI reino, fin úlumo, y a la vez, construcción histórica, como centro de la predicación de Cristo, y a la Iglesia como la comunidad organizada, instituida sobre la fe en la resurrección, posterior por tanto a la pascua, misionera, que busca la fraternidad humana en la rea- 
lización de su designio salvífico. Sus formas han evolucionado, y tendrán que seguir evolucionando para que se produzca el triunfo del amor y de la liberación. ${ }^{54} \mathrm{La}$ Iglesia participa del plan de Dios, pero la salvación no se reduce a la acción eclesial. "En un mundo radicalmente escindido, la función de la comunidad eclesial es luchar contra las causas profundas de la división entre los hombres." 55

La TL reivindica con fuerza la ligazón imprescindible entre el amor eficaz al prójimo y el sacrificio expresado en el rito de la misa, entre el culto y la acción en procura de la fraternidad humana. ${ }^{56} \mathrm{La}$ eclesiología en la TL trasciende efectivamente la modernización reformadora postconciliar en un campo especialmente difícil, dados el verticalismo y la disciplina férrea de la Iglesia instilucional. Al trascender aporta a la Iglesia un llamado especialmente valioso a encontrar fuerzas en sl misma para revolucionarse y marchar eficazmente con el pueblo cristiano pobre y oprimido.

La TL es una de las fuentes más imporantes de la nueva manera de vivir la fe y del actuar cristiano, que pugna por extenderse en la América acual. Reflexiona sobre las prácticas y sobre las estructuras significativas de la Iglesia y de las sociedades, ayuda a comprender y a molivar, a profundizar en la interpretación de las Escriuras, la tradición y el magisterio eclesí́stico, a fundamentar, desde la religion, actuaciones en favor de la liberación. ${ }^{57}$ Contribuye a modificar positivamente el acervo cristiano en cuanto a principios y comportamientos, y sienta las bases de una ética que considera al hombre inmerso en sus condiciones de existencia y en los conflictos sociales, incluida la lucha de clases.

Quisiera terminar estar breve exposición de los temas de la TL cilando algunos textos que ilustren y ayuden a presentar sintéticamente los puntos de vista principales.

"La TL no es únicamente, como algunos lo piensan aquf, una teologia que pone el acento en lo social. Es eso, pero es más; intentamos situamos allí donde no es posible separar solidaridad con los pobres y espiritualidad, amor fratemo y oración, ser humano y Dios. Eso es ser cristiano, discípulo de Cristo, Dios y hombre. ${ }^{.58}$

"La teología debe ser un pensamiento crítico de sí mismo, de sus propios fundamentos [...] en plena posesión de sus instrumentos conceptuales [...] también una actitud lúcida y crítica respecto de los condicionamientos económicos y socioculturales de la vida y reflexión de la comunidad cristiana, no tenerlos en cuenta es engañarse y engañar a los demás. Pero además, y sobre todo [...] la teoŕa de una práctica determinada. La reflexión teológica sería entonces, necesariamente, una crítica de la sociedad y de la Iglesia, en tanto que convocadas e interpeladas por la palabra de Dios; una teoría crítica, a la luz de la palabra aceptada en la fe, animada por una intención práctica e indisolublemente unida, por consiguiente, a la praxis histórica" 59

"La TL parte decididamente de la fe. Esta es su primera palabra; en el acto de captar la realidad en su iniquidad y en la opción por las mayorías humillladas re- 
sulta vivo el horizonte de la fe en el que se mueve vitalmente el cristiano. El objeto de la teología es Dios, el Dios revelado; pero no sólo El; lo son también todas las cosas en cuanto vistas a la luz de Dios. Esto significa que también es propio de la teología hablar de la historia, política, economía, sociologia y cualquier cosa que se contemple a la luz de Dios [...] Cuando, por ejemplo, piensa sobre realidades complejas y 'seculares' (la sociedad, los mecanismos del empobrecimiento, las organizaciones populares y la política del trabajo, la función del Estado, etc.), necesita conocer analítica y críticamente estas realidades [...] Una vez descifradas [...] el teólogo pasa a leerlas a la luz de la fe, de la tradición, del magisterio y la razón teológica." 60

"La TL, finalmente, intenta articular una lectura de la realidad a partir de los pobres y en interés por la liberación de los pobres; en función de esto maneja las ciencias del hombre y de la sociedad, medita teológicamente y postula acciones pastorales que ayuden a caminar a los oprimidos."61

\section{$\mathbf{V}$}

Las críticas a la TL a partir de su supuesta adhesión o influencias marxistas son una constante desde su surgimiento; a ellas aludíamos en un punto anterior. Entre otras razones que llevan al mantenimiento de esas críticas están los propios límites de la modemización postconciliar de la Iglesia: la reforma siempre se ha propuesto evitar la revolución, y el manxismo-leninismo expresa el proyecto más revolucionario de nuestra época a escala mundial.

Cuando surgió la TL, la bancarrota del desarrollismo, la revolución cubana y demás factores a que nos referimos antes, propiciaban en América Latina un clima favorable al despliegue de acciones y accitudes revolucionarias y también al desarrollo de pensamientos y teorías que analizaran con radicalidad las causas del mantenimiento de estructuras de explotación y opresión en el continente, y mostraran caminos ciertos para una práctica que produjera la eliminación de esas estructuras. Todo ello dio impulso a la renovación y el desarrollo de las ideas marxistas y a una expansión notable de su influencia social y política. A pesar de las críticas y de los prejuicios mutuos, la asunción o utilización de elementos del marxismo por la TL no resultaba demasiado difícil.

Más de 15 años de violentas luchas de clases, la reorganización a sangre y fuego de la hegemonla imperialista y burguesa, amenazada por el rechazo activo de organizaciones y pueblos durante el proceso de modemización y la crisis que le ha sucedido, el afianzamiento de la revolución cubana, el triunfo sandinista y la revolución salvadoreña, marcan el camino recorrido hasta hoy. En el marco de un desarrollo mayor y más complejo de la dominación imperialista y de los lazos capitalistas entre Estados Unidos y América Latina, pero también de mucha más concientización a escala popular, con la consecuente identificación de la opresión, la explotación y sus causas, la lucha ideológica organizada ha pasado a primer 
plano; la multiplicación continuada de medios técnicos de comunicación y el hábito de consumir sus productos potencia las posibilidades de influir y formar opinión.

La democratización, vista y utilizada desde el lado burgués, pretende cumplir un papel de movilizador respecto a la posibilidad de revoluciones liberadoras, aunque aceptando la ampliación de la politización, pero analizándola hacia prácticas e ideolog [as que no disputen el poder político imprescindible para llevar a cabo la liberación. Lo que se salga de ese marco "democrático" es tachado de "extremismo," convenientemente clasificado como malo e igualado a su supuesta pareja, el de derecha. Las organizaciones sociales y políticas y las ideas pueden formar un espectro amplio siempre que no se salgan de los márgenes de esta nueva estructura de dominación.

Al marxismo se le combate de las formas acostumbradas, pero además se insiste en que ha entrado en definitiva decadencia, junto con sus proyectos, sus organizaciones y el campo socialista. En la actualidad, las crílicas a la TL en lo que toca al marxismo insisten en el riesgo del ateísmo, de la eliminación de la fe, en el carácter supuestamente muy limitado de la doctrina marxista (se basa sólo en el proletariado, no en todos los pobres; pretende una liberación socioecómica solamente, no integral; etc.), en que el maxxismo favorece el odio y la lucha de clases, que está ligado a concepciones totalitarias que aspiran a sustituir el capitalismo por regímes en los cuales a lo sumo se obtienen ventajas sociales a cambio de libertad, y que los países con poderes socialistas son ejemplos de fracaso de los proyectos de liberación.

Se intenta que los teólogos de la liberación insistan en lo limitado de su relación con el maxxismo, para sobrestimar el papel de la cuestión en la TL y alejarla en lo posible del terreno central de sus postulados; en ese terreno resulta muy natural su coincidencia con quienes luchan por la liberación de los pueblos. En la medida en que esa maniobra prosperara, la altemativa que quedaria a los teólogos que no expresaran su distancia sería la de "parecer marxistas".

No pretendo terciar en los debates intraeclesiales, pero sí hacer algunos comentarios acerca del marxismo-leninismo en relación con el tema en cuestión, porque resulta muy necesario clarificar todo lo que ayude a un encuentro que es imprescindible, 62 y más aún cuando, en medio de una terrible situación de crisis y miseria de las mayorías, no se está en una situación revolucionaria en la mayoría de los países del continente.

El marxismo es, ante todo, la teorín de la lucha de clases en el mundo contemporáneo, dirigida a derrocar a los explotadores, a establecer la liberación nacional y el socialismo, extender el internacionalismo en el mundo y profundizarlo, crear las bases y desarrollar una nueva cultura totalmente opuesia a la que ha regido, basada en la dominación de los hombres; cultura de la organización social, de la educación, de las actitudes y conductas individuales, que en el curso de la lucha y las transformaciones sociales ayude a los hombres a volverse ca- 
paces de construir el mundo sobre nuevas bases. Todo ello supone y exige, naturalmente, una revolución social, a la vez que define el conlenido de su largo y necesariamente ininterrumpido proceso.

Lo anterior es fundamental y no entorpece el caracter de epistemologia por excelencia que tiene el marxismo-leninismo para las ciencias sociales y humanas. Es más, en el marxismo resultan de imprescindible interrelación los aspectos ideológicos y científicos, cuestión fundamental de método que no es el caso tratar aquí. Si tendemos a superar los "malos entendidos" a que lleva, sobre todo el inmenso poder social que hasta hoy han tenido el capitalismo y su cultura, el marxismo puede brindamos una ayuda incomparablemente mayor con su método esencialmente revolucionario y con sus capacidades de ir muy por encima de sus propias condiciones de producción y de prefigurar nuevas relaciones humanas en una nueva sociedad en proceso de liberación.

Para el marxismo, el cambio social liberador sólo puede ser obra de los explotados mismos, y ellos se cambiarán a si mismos en el proceso de cambiar sus circunstancias. ${ }^{63}$ Esto se repite una y otra vez en los textos desde Marx hasta hoy. Pero hay algo aún más importante: ese proceso ya ha sido emprendido prácticamente en el mundo, a partir de la inspiración marxista, desde hace un siglo, y ha constituido la praxis e involucrado las vidas de centenares de millones de personas, convirtiéndose en la más rica experiencia histórica y la más amplia realidad de procesos de liberación existente en el mundo actual. Sus logros, sus insuficiencias, sus errores y sus proyectos son insoslayables para todo planteamiento serio de participación y de reflexión sobre la liberación de la humanidad.

Es necesaria la organización polílica, e incluso político-militar, para enfrentar la opresión organizada y poderosa, basada en siglos de poder y articulada desde la instancia internacional hasta la del consenso de una parte de los oprimidos mismos. Existe la lucha de clases, es un hecho; afortunadamente existe, para que pueda exister la fratemidad humana y llegar a predominar el amor. ${ }^{64} \mathrm{La}$ liberación es un largo y duro proceso que hay que recorrer. ${ }^{65}$ Las clases sociales no son simplemente los sujetos de un conceplo con el que denotamos una situación y unas estructuras, porque la posición de clase sólo se establece totalmente en las luchas de clases. Sostener que el marxismo fomente el odio entre las clases es absurdo; en el mejor caso, éste ha sido bien alimentado durante muchísimos siglos. Los movimientos de liberación inspirados en el marxismo se proponen precisamente eliminar las causas que engendran esos odios, ir hacia la eliminación de las clases mismas y fomentar eficazmente relaciones directas, fraternales y humanas entre todos los hombres. ${ }^{66}$

Los pueblos que tienen ya poderes revolucionarios se ven obligados a luchar una y otra vez contra el inmenso poder que todavía tiene el capitalismo a escala internacional; un poder que se les opone en todos los terrenos para tratar de hacerlos fracasar, tienen que luchar contra el subdesarrollo, que va desde la tecnología hasta las cabezas de los hombres, un pozo de las mejores intenciones y 
un peso muerto que tira en dirección contraria a la liberación. La unidad, la organización firme, el manejo de los recursos, las grandes empresas de transformación de la vida económica y social, no son caprichosas elecciones: son los caminos que hay que recorrer.

Claro está que existen enormes tensiones entre el proyecto y los ideales socialistas de liberación y la formación y cristalización de las instituciones a través de las cuales debe emprenderse y adelantarse la transición hacia la sociedad sin clases y liberada La literatura marxista está llena de planteamientos y de polémicas alrededor de ese problema crucial, desde décadas antes de la Revolución de octubre hasta la actualidad. En la práctica, se trata de un proceso muy difícil, en el cual se recae una y otra vez en la reproducción de aspectos de una sociedad regida por el individualismo y el egorsmo, en el cual se sale angustiosamente hacia adelante, una y otra vez, ${ }^{67}$ y se está cada vez más lejos del modo de vida burgués y se logran cada vez más relaciones fraternas entre los hombres, más pacificación de la existencia y más capacidades sociales para avanzar hacia el comunismo.

La participación de todos los que están comprometidos con la liberación de los oprimidos en el análisis crítico y apasionado de las experiencias de los pueblos que han tomado el camino de la liberación, tiene que resultar sumamente positiva para nosotros. Además, es indispensable para los mismos críticos militantes: forma parte de su asunción del acervo de la praxis de liberación y facilita que puedan pensar más acerladamente, con sus propias cabezas, los modos y vías por los cuales harán efectivos sus compromisos. Lo que resulta imposible es situarse en una fria y neutral posición, como si el marxismo y el socialismo carecieran de realidad y de consecuencias prácticas y teóricas.

Volviendo al terreno conceptual, quisiera hacer todavia dos precisiones. Primera la cuestion de la historicidad: el marxismo tiene derecho a que se le estudie y conozca a partir de sus propios aportes al conocimiento social. El marxismo no es algo dado de una vez y para siempre, igual a sí mismo; sus núcleos fundamentales han sido una y otra vez desarrollados durante casi siglo y medio por los aportes teóricos de sus principales pensadores, y a la vez han sido afectados por el movimiento del capitalismo, el surgimiento y desarrollo del socialismo, la revolución y la contrarrevolución, las practicas, ideologfas y ciencias, el movimiento en fin del complejo constituido por la reproducción y el cambio de las formaciones sociales y las percepciones que de esos procesos se tienen.

Es cierto que la producción térica goza de una relativa autonomía y que la incorporación de nuevas ideas, así como el influjo de nuevas circunstancias, se asumen casi siempre desde y sobre el saber y las creencias intelectuales cristalizadas anteriormente. AsI, el pensamiento producido específicamente en cada momento histórico determinado expresa a la vez una continuidad de pertenencia teorica e ideológica, es objeto de unas determinadas "traducciones" de lo nuevo al conjunto donde se inscribe y muestra una complejidad en la cual pueden distinguirse variantes y ambigiledades. 
Es muy importante -y por demás imprescindible en todo caso de interpretación y apropiación - comprender entonces al marxismo leninismo poniendo cada una de sus manifestaciones en releción con sus condiciones históricas de producción, a la vez que con la totalidad teớica a la cual pertenece. Ello aumenta extraordinariamente la riqueza y las potencialidades de su utilización. Y permite, entre otras cosas, apreciar cómo ha ido ampliándose -en un largo proceso no exento de contradiciones y retrocesos parciales- el campo teorico del marxismo leninismo, en las formaciones sociales y en los modos de cambiarlas hacia el socialismo y el comunismo, en la comprensión de diversidad de ámbitos regionales del mundo, en los procesos históricos, el lugar, los problemas y actividades del individuo.

Una segunda cuestión es la relativa al estatuto científico del marxismo como antítesis de la fe, que se formula o alude, de maneras variadas, en las creencias de que el marxismo elimina toda la fe al reducirla a "política" o a "ciencia" o a "materialismo" filosófico. Frialdad absoluta en la que nos resulta imposible reconocernos. En primer término, nadie participa y cree en un proyecto de cambio tan radical de las condiciones de existencia y actuación que han parecido "naturales" e inevitables a lo largo de la historia, como es el proyecto de liberación socialista, sin poseer una intensa fe. ¿Cómo puede si no representarse el individuo la sociedad que vendrá a ponerla en relación con sus valores y actuaciones en su vida inmediata? ¿Cómo podría, sin esa fe, enfrentar los trabajos, los sacrificios, los riesgos, los fracasos, la esperanza, la solidaridad, la entrega?

En segundo lugar, el marxismo proclama por sí mismo ese carácter suyo de conciencia social que va creciendo; es una de las formas principales de esa interrelación entre los aspectos ideológicos y científicos a que aludía antes. Si recorremos, por ejemplo, los planteamientos más importanes de nuestra revolución a lo largo de su historia, los conceplos de moral, desinterés, espíriu de sacrificio, solidaridad, pureza revolucionaria, honestidad, superación, entre otros, campean por textos, discursos y declaraciones; 68 su significado se enseffa en la práctica, en las escuelas y en las demás instituciones de nuestra sociedad.

En lo que toca a la teoría, la cuestión se plantea haciendo del ateísmo el centro del marxismo, el cual seria portador de antítesis irreductibles de "cienciareligión" y "materialismo-religión." Se lo considera asi el simple continuador ahistórico de corrientes fundamentales del pensamiento que acompanaron y animaron el triunfo de la burguesía en Europa, entre la ilustración a las revoluciones de 1848. El marxismo leninismo sería así ciego y sordo a sus propios principios teóricos, y también a su historia y a la del movimiento histórico al cual responde, esto es, el de las revoluciones de liberación y en contra del capitalismo mundial.

No hay que olvidar que desde su origen la crílica de Marx a la religión tiene unos punlos de partida ajenos y opuestos a los del primer pensamiento burgués. Pero lo fundamental de Marx, Engels y Lenín en la comprensión de la religión, 
en mi opinión, no se encuentra en los pasajes o fragmentos donde hablan de religión solamente, ni siquiera principalmente, sino en el conjunto de su teoria de las sociedades. Ella permite acercarse a este fenomeno, así como a otros, en relación con las formaciones sociales y sus particularidades, con las clases y las luchas de clases, con la conciencia de clase, con las relaciones entre individuo y clase, con las revoluciones y con la transición al socialismo y al comunismo.

La cuestión religiosa es uno de los retos planteados al marxismo-leninismo por su universalización efectiva, felizmente en curso en los dos tercios de siglo transcucridos desde la muerte de Lenin. En Este, como en otros campos, se ha pagado tributo al eurocentrismo y a los consiguientes traslados mecánicos más bien que transferencias culturales. El mismo diálogo cristiano-marxista europeo, sin duda un progreso, nos muestra su completa inadecuación e insuficiencia ante las necesidades y las ideas de cristianos y marxistas en América.

Los cristianos arrastran el pesado fardo ideológico del anlicomunismo simple, feroz o elaborado, que la hegemonía burguesa les trasmitió, junto con el Lemor a ser perseguidos o a que les quitaran su fe. Ese anticomunismo les oscureció lo básico, la explotación y la opresión de las mayorías bajo el régimen capitalista. Los marxistas tenemos en contra de nuestra valoración de la cuestión religiosa no sólo los prejuicios alimentados por la larga historia de oposición de las iglesias a las revoluciones liberadoras y al socialismo, sino también el riesgo de aferramos a fórmulas que tuvieron valor ideológico, pero que han sido dejadas atrás por el desarrollo social e intelectual y también por la propia universalización de marxismo-leninismo.

Por fortung, en este campo así como en los demás, la praxis revolucionaria impulsa decisivamente el desarrollo del marnismo. El respeto mutuo alimentado por la coincidencia en la defensa de los derechos populares se vuelve admiración mutua y fraternidad probada cuando se llega a compartir la lucha y la entrega 69 Y en el terreno de la teorla sirve como presupuesto ideológico para replantear más profundamente y comprender mejor la religión, las iglesias, los creyentes y los papeles que ellos puedan desempentar en el curso de la liberación y en los regímenes de transición.

Sin intentar desarrollar el tema, que ya está recibiendo aportes notables, del lado cristiano y del lado marxista, ${ }^{70}$ quisiera, sin embargo, hacer unos comentarios finales.

Es cierto que la progresiva capacidad de la ciencia para explicar los fenómenos de la naturaleza - y de la técnica para aplicarla y revolucionar la vida con sus productos - contribuye a disminuir unos de los soportes de la religiosidad, la sacralización de las relaciones hombre-naturaleza, o la mediación sobrenatural para explicar una parte de ellas. Pero es fácilmente visible que la contradicción vida-enfermedad-muerte, ligada aparentemente a la relación hombre-naturaleza, es permanente para todos, y que la contradicción bien-mal, ligada a lo social, aparece con frecuencia en los problemas, en la vida diaria y en las concepciones que sobre 
ellos se tengan. En realidad pueden encontrarse los condicionantes sociales de ambas contradicciones, aunque con entidad y mediaciones diferentes, y asi conocerlas mejor ya que forman parte del referente religioso de innumerables personas.

De lo que se trata es de mantener la distinción entre conocer e iluminar. La razón o la ciencia no eliminan a la religión. En el proceso de liberación se extienden extraordinariamente las explicaciones naturales de los fenómenos naturales, pero to esencial es que se extienden extraordinariamente las explicaciones sociales, y en buena medida, socialistas, de los fenómenos noturales y sociales. Se forma un nuevo medio ideológico, dentro de cuya complejidad lo natural y lo social encuentran explicaciones referidas a las luchas de clases, a la liberación, a la lucha por el socialismo y al anti-imperialismo, al internacionalismo. Ello no agota, sin embargo, el modo de vivir las relaciones con los fenómenos naturales y sociales. El lugar o los lugares que vaya ocupando la religión en ese medio ideológico dependen de las condiciones concretas que ella tenga en cada país, de su historia, de su participación en la vida social, etcétera

La fuerza del proceso revolucionario -es nuestra experiencia, por ejemplopotencia inmensamente las capacidades del individuo de cambiar, elevarse, hacerse superior a sus circunstancias y fijar actitudes y conductas nuevas y fratemales. La convicción, la pasión, el entusiasmo, la fe, el desinterés, la entrega, la capacitación, plasmados en acción continuada y en organización, reproducidos cada vez en mayor número y calidad por el proceso múltiple de la educación social, en el cual los papeles de educador y educando se mutan e interactuan, van estableciendo unos patrones de conducta y unas representaciones espirituales-que pueden configurar una ética, al menos parcialmente- de lo justo, lo humano, lo digno, lo que se debe hacer en la vida, las condiciones que esperamos que reúnan nuestros familiares y demás allegados, los principios que es honesto sostener.

Todo lo anterior es vida espiritual, es organización progresiva de las normas que deben regir la revolución y prefigurar las sucesivas revoluciones que esas mismas normas sufrirán en su intento por crear una nueva moral, basada en una sociedad liberada, lo cual sucede en medio de angustiosas recaídas en la manera prerrevolucionaria de vivir y sin fáciles y aplicables recetas generales. Serla injusto y un error de gran trascendencia no ver al socialismo ni al marxismo impulsando ese complejo proceso de liberación. Śblo los explotadores y opresores sildrian ganando de ello.

\section{VI}

La "Instrucción sobre algunos aspectos de la Teologia de la Liberación"71 fue el documento vaticano que más duramente criticó a la TL. Todos los teólogos comprometidos con la TL y numerosos publicistas cristianos contestaron a esas críticas con una avalancha de argumentos y aclaraciones, a la vez que ofrecieron sintesis de las posiciones de la TL que ellos mismos asumian. Las publicaciones progresistas cristianas o afines dedicaron gran espacio a defender la TL. Las co- 
munidades eclesiales de base, otras organizaciones cristianas y religiosos y lós obispos comprometidos se unieron en la defensa de la TL y del derecho de las:cristianos latinoamericanos a vivir su fe desde su propio mundo.

Dos afos después la situación ya no es la misma. La "Instrucción sobre. libertad cristiana y liberación," publicada el 5 de abril de 1986, segundo documento vaticano sobre el tema de la liberación, ya anunciado en el primero, ${ }^{72}$ parece expesar, en su tono positivo $y$ en la valoración que hace de las comunidades de base, del amor preferencial por el pobre y de lo que llama misión liberadora de la Iglesia, el inicio de una "nueva etapa." Diversos té́logos han analizado la nueva "Intrucción" desde los puntos de vista de la TL, la mayorfa de ellos ha expresado reservas hacia la comprensión real que pueda tener de esta teologla producida en América. ${ }^{73}$ A pesar de ésta y de otras observaciones. criticas, se reconoce el lenguaje moderado y el tono constructivo del documento.

Un impacto positivo mucho mayor ha tenido la carta enviada por el Papa: Juan Pablo II a la conferencia episcopal brasilefla (9 de abril de 1986), poco después de su encuentro en Roma con 21 obispos representantes de aquella conferencia El encuentro es considerado también como muy positivo. Además de celebrar que la Iglesia brasilena haga una opción preferencial por los pobres y participe en el reclamo de reformas distributivas (como la agraria), los derechos humanos y los servicios sociales, el Papa ha calificado a la TL de "no sólo oportuna sino útil y necesaria," y la ha llamado a cumplir con un conjunto de requisitos para lograr mantener una "plena adhesión a la constante enseffanza de la Iglesia en material social [...] plena fidelidad a la doctrina de la Iglesia," ser nueva etapa teológica en estrecha conexión con las anteriores, y a la vez "inspirar una praxis eficaz" en favor de los derechos sociales y humanos y colaborar en la "construcción de una sociedad humana basada en la fraternidad y la concordia, en ha verdad y en la caridad," que logre lo que no pueden lograr, dijo, el capitalismo ni el socialismo. ${ }^{74}$

El Papa exhortó a la Iglesia brasilefia a desempeffar un papel principal en el desarrollo de la TL, como un servicio no sólo al Brasil, sino América Latina y a otras regiones del mundo con problemas análogos.

Ya se tengan opiniones optimistas respecto a las valoraciones más recientes de las altas jerarqufas eclesiásticas y al efecto favorable que ellas puedan tener en el desarrollo ulterior de la TL, o se vean con reservas sus insuficiencias y motivaciones, me parece indiscutible que la TL tiene suficiente entidad propia para seguir desarrollándose como cuerpo de pensamiento, ligado a una realidad tan acuciante como la latinoamericana, en cuyas necesidades más profundas encuentra su razón y su fuerza. ${ }^{75}$

La importancia que da Juan Pablo II a la doctrina social de la Iglesia puede tener aspectos positivos para la renovación cristiana en un medio como el de América Latina; la ortodoxia ideológica que reclama vigorosamente y que incluye una critica severa del socialismo y del marxismo, ${ }^{76}$ puede ser, sin embargo, un 
factor negalivo al chocar con la necesaria originalidad de pensamiento y de actuación que tienen los movimientos populares cristianos y la TL. La autoridad jerárquica sigue considerándose intangible, por lo que las iniciativas de las comunidades siguen sumamente condicionadas y la aclividad de los pensadores, en alguna medida, sujeta a los criterios de sus superiores.

Un complejo de factores intraeclesiales y extraeclesiales afecta al curso futuro de la TL. Es indudable la imporancia, entre éstos últimos, de la ampliación del campo popular en América. Esta ampliación se debe al avance de las revoluciones de liberación de algunos países y a las transformaciones a favor del pueblo en otros; sabemos las circunstancias diffciles en que se libra en la actualidad la lucha popular. $Y$ en muchos lugares la TL puede sentir la presión para que el movimiento cristiano atempere su mensaje y sus prácticas de liberación dentro del espectro de actitudes válidas para el sistema democrático burgués, complemento secular de la pretensión de espiritualización de corte tradicional que se pide desde dentro de la misma Iglesia.

¿Le tocaría a la TL el destino de ser finalmente una vanguardia modernizadora de la Iglesia en América Latina, yendo mucho más allá que la modernización eclesial europea, pero no tan lejos como el proyecto que formulo? $\downarrow O$ por el contrario, mantedrá y profundizará su mensaje de liberación contribuyendo a una renovación revolucionaria del cristianismo y al proceso liberador de los pueblos?

Creer que puede haber una correspondencia simplista entre la TL y sus condicionamientos sociales e intraeclesiales inmediatos sería quedarse con la primera altemativa. La realidad histórica que cuenta es, sin embargo, la de una inaplazable época de luchas por transformaciones liberadoras en América Latina y el Caribe. Unas luchas que comprometerán a los cientos de millones de explotados y oprimidos, en su mayorla cristianos. A sus necesidades responden las luchas políticas de los pueblos y la participación de los cristianos en ellas, también responden a ellas, en su especificidad, los movimientos populares cristianos y la TL. A esta última le es intrínseca la reflexión desde la praxis cristiana de liberación; lo que cabe esperar de ella es que tense sus fuerzas y ofrezca profecla, espiritualidad y utopla al pueblo cristiano - también la teorla se convierte en fuerza material si se encarna en la masa del pueblo-, esto es, que concurra como parte y componente del proyecto de liberación que es imprescindible levantar por sobre los asuntos de cada día, dando sentido y vicioria al sacrificio y a las luchas de los pobres del continente. 


\section{NOTAS}

1. En adelante la lamaremos TL.

2. En su Teología de la liberación. Perspectivas (1971. Ciro la edición del Centro de Estudios y Publicaciones, Lima: CEP, octubre de 1984), Gustavo Gutierrez cita con rigor y prolijidad a cuanto teólogo se ha referido en Europa a las cuestiones que trata en su libro. Diez años después, Leonardo Boff, en su Iglesia: carisma y poder, (Sanunder. Sal Terrac, 1982), tiene entre sus 402 citas a los representantes de la teologla tradicional y modema europea, como le recuerda el autor al cardenal Ratzinger en carta respuesta del 24 de agosto de 1984.

3. Mensaje papal del 11 de septienbre de 1962, un mes antes del inicio del concilio. Cirado por Gustavo Gutiérrez, "Vaticano II y la Iglesin latinoamericana," Diakoní, 1985, 36. 293.

Juan XXIII dirigió por primere vez une enciclica no s6lo los cetolicos, sino "a todos los hombres de buens voluntad" (Paz en la tierra), apoyo la coexistencia pacifica, reconoció la libertad de conciencia, elimino la práctica de las excomuniones, declaró la utilidad del dílogo entre católicos y comunistes, entre creyentes y ateos.

4. "S6lo en el Concilio Vaticano II la Iglesia ha comenzado a abandonar francamente la mentalidad de cristiandad. Epoca hsibrica fenecidn... cuatro siglos antes" (Gustavo Gutitrez, Teologb..., ed. cit., 73, n. 5). "En el primer mundo el concilio llego con un retaso de siglos" (Jon Sobrino, "Varicano II visto desde America Latins," en Diakonb, $1985,36,319$.

El primer Concilio Vaticano (1869-1870), el cual proclanó la infalibilidad pontificin, se hizo bajo el signo de Syllabus, condenación eclesística expresa de prícticamente todo movimiento de progreso en la socieded, le pollicio, la ciencia y la religión.

5. Enclclicas, constituciones y carlns apostólicas como Mater el Magistra, Pacem in Terris (ambas de Junn XXIII), Lumen Gentium Gaudium et Spes, Populonwn Progressio, Ocrogesima Adveniens, y Evangelii Nurtiandi se refirieron a transformaciones de la liturgia, In libertad religiosa, el ecumenismo, la formación sacerdotal, la actividad misionera los medios de comunicación socinl; se dieron pasos parn fortalecer la colegialidad, el papel de los laicos en la Iglesia, el sirnodo.

6. Denominación no mury precise bajo in que queremos referimos al conjunto de actividades y de forma organizalivas mis o menos duraderas puestas en profetica por los sectores mís avanzados de Iglesis, sobre todo los laicos, pero umbien, y muchas veces guíndolos o inspirandolos, miembros del clero. Se refiere a la actividad pastoral y . luchas socinles.

7. Son emergas las palabras del destacado téblogo Johnnn B. Metz en Niaragun (10 de abril de 1980), "Vengo de un pats y de una culurn en los cuales tados los movimientos de libención han tenido lugar sin la Iglesia o contra la Iglesia, por ejemplo la reforma, la ilustración, la revolución francess $y$ la revolución rusa [...] La identidad cristians en Europa no esta amenazada por la pobreza o por la opresión, sino por la riqueza y el consumismo. Por eso el cristianismo entre nosotros ha decaldo hasta convertirse en una religión burguesa. Y si eso no se supera, el cristianismo va a morir entre nosotros." Nicar Guac, 1981, 5, 32).

8. Jon Sobrino, op. cit., 315.

9. Gusuvo Gutierre, Teología de la Liberacion. Perspectivas: "Vaticano II y la Iglesia letinoamericana." Pablo Richned, La Iglesia Latino-americana entre el temor y la esperanza, San Jost: Departamento Ecumbnico de Investigaciones, DEI, 1980. Leonurdo y Clodovis Boff, Como fazer Teologia da Liberlaceso, Perropolis: Ed Vozes, 1986, capt. V Jon Sabrino, op cir.

El jesuirn Roberto Oliveros, en una obre de obligsda consulta, Liberación y reologia. Gánesis y crecimiento de una reflexión (1966-1976), Lima: CEP, 1977, 479, expone, 
entre ofras, las posiciones de Hugo Assman (Opresión-Liberación. Desafio a las cristianos, 1971) y de Juan Luis Segundo (De la sociedad a la teologia, 1970).

10. Conviene recordar un texto de Marx, más repecido que eswdiado, "al considerar tales revoluciones impora siempre distinguir entre la revolución material de las condiciones económicas de producción -que ee debe comprobar lielmente con ayudn de las ciencias fisicas y natureles- y las formes jurídicas, polticas, religiosas, arústicas o filosóficas; on une palabn, las formas ideológicas bajo las cuales las hombres adquieren conciencio de este conflicto y lo resuelven" (Prólogo a la Contribución a la crítica de la economin polfica, de 1859. E subrayado es mlo).

11. Desde la actividad de obispos como Manuel Lamaín y Helder Ciman, quienes presidieron el CELAM que vivió el Vaticano II y promovió su difusión en América mediante acciones que culminaron en Medellín (1968), la actitud de los episcopados brasilefio y chileno en el concilio, hasta la firma por 9 obispos brasileños del "Mensaje de obispos del tercer mundo, respuesta " Populorum Progressio" (1967), haste el humildisimo origen de las comunidades eclesiales de base (CEB) en el Brasil, que cuenta Lenoardo Boff en Eclesiogenesis. Las comunidades de base reinventan la lglesia. Santander. (Sal Terrae, 1979, 13-14), o Fri Beno, en $O$ que (Comuridade Eclesid de Base, Sao Paulo: Ed. Brasiliense, 1981).

La vidn y la muerte del sacerdoce y sociólogo colombiano Camilo Torres Restrepo se convirtieron en ejemplo supremo de compromiso cristinno ssumido haste sus últimas consecuencias. En su "Mensaje a los cristianos" habia escrito: "la revolución no solo es permitida sino obligatoria para los cristianos que vean en ella la única manera eficaz y amplia de realizar el amor para tados... es necesario entonces quitarles el poder a las minorins privilegiades para dárselo a las mayortas pobres... Yo he dejado los privilegios y deberes del clero, pero no he dejado de ser sacerdote. Creo que me he entrgado a la revolución por amor al projimo" (3 de agosto de 1965. En Camilo Torres: Liberación o muerte, Le Habena: Instiuto del Libro, 1967, 37-38).

12. L y C. Boff, Como fazer Teologia da Liberlacao, ed. ciL, 97.

13. Entre ellos, los tenidos en La Habana, Bogotí y Cuemavaca (junio-agosto de 1965); los continentales de la Comisión de Iglesis y Sociedad en América (ISAL), protestante, en 1966, 1967 y 1971; los preparntorios de Medellín tenidos en Melgar (Colombin) e Iupoin (Bresil), en 1968 (ver R. Oliveros, op. cir., partes I y II; L y C. Boff, op. cis., 97-99; victorio Anya, "L teologla de la libenacion: sproximación hiscórica," en serie Iglesia y Religión, No. 25-26, Mérico DF: Centro Antonio de Montesinos s/f).

14. "Esto indice que estamos en el umbral de una nueva tpoca historica de nuestro continente, llere de un onhelo de emencipación toul, de liberación de tode servidumbre, de maduración personal y de integración colectiva. Percibimos aqui los prenuncios de la dolorosa gestación de una nueva civilización."

15. El imperialismo umbien percibió la peligrosidad de ese encuentro: "Debemos tener cuidndo con L I Iglesin latinoamericana, pues si cumple los acuerdos de Medellín atents contra nuestros intereses," informa Nelson Rockefeller al regresar de su viaje por América Latins, en 1969. Y en 1970, la CIA recomendó pare Bolivin lo que pronto se generiliz6 en las agresiones los cristianos más avanzados: "No se debe atacar a In Iglesia como instiunción... sino a une parte de ln Iglesia, ln más evanzada," (Tomado de Jon Sobrino, "El Varicano y la teologla de le liberación," en Controversia, 1985, 127, Bogoti: CINEP, 1985, 49). En 1969 el Deparumento de Eslado habin encargado a la Rand Corpontion de Califomir un eatudio sobre los cambios en curso en la Iglesin carblice

16. "Se muestr la ambigujedad y raroceso del Slnodo de 1974, con respecto a Medellin" (R;. Oliveros, op. cit., 119).

17. Una exposición de todo este proceso puede hallarse en Jose Miguel Munifriz, "Lo teologia de la liberación en los documentos de la Iglesia: Medellin y Pueblen en Anthopas, 1985, 2111, Caraces, 45-60. 


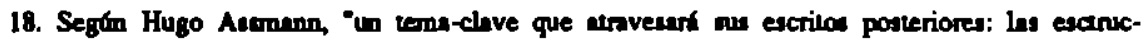
uras institucionales de le Iglesir ren y, a partir de an motriz objetive los criterios

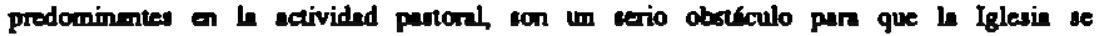

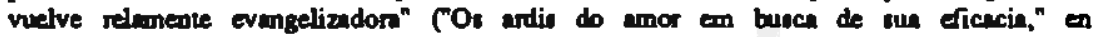
Paspectiva Teológion, 1983, 15, 225).

19. Ver, por ejemplo, an descripción precies del tipo de Iglesis mademizade dentro del

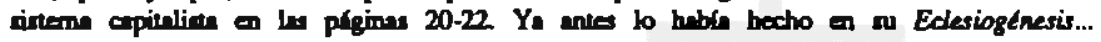
(ed. cit., ver, por ej., Pp. 53-61).

20. Gustavo Gutierrez pintn muy bien a la que aún ven la Iglesin camo "el sitio en el que nos sentimos comodos on mondo que no es el de los pobres. Me refiero a categorins meninles, pero tambien a actiude efectivas y enocionales, a una complicidad profunda y ruril con un ambiente distinto $e$ incluso opuesto al de los pobres. Es por eso que el mundo de los oprimidos conscientea de as situación y en lucha por us derechos resules extraĩo y a veces bostil a lo Iglesia, le impide descansar, encontrarse en cass, sentirse conforable" (Comunidedes cirtinnes de base," en Acompalands a la comenidad, Lime: Cantro de Estudion y Publicaciones (CEP), 1982, 80-81).

21. Pan el pertodo harte 1971, ver, entre otros, Gustovo Gunienre Teologí de la liberacion, ad. cil, cyítulo 7 ("Le Iglesis en el proceso de liberecion"), 125-164.

La publicación orderada de cienlos de documentos por el CEP de Lims, constinuye uno fuente muy valioss: Signos de liberación. 1969-1973 (noviembre de 1973), Signos de luche y esperanze, 1973-1978, (septiembre de 1978) y Signos de vida y fidelidad, 1978. 1982), (febrero de 1983). E primer volumen de "Signos" fue Signos de renovación 1966. 1969. publicado por ln Comisión de Episcopal de Acción Socinl, Lime, 1969.

22. Gurno Guiterex, Teología de la liberación, ed. cit; "L fuerra histórica de los pobres," en Signas de luche y esperanza, ed cil., XV-XLII; Pablo Richard, "para entender he toologin de ln libereción," en serie Iglesia y Religión, No. 25-26, ed cir; L y C. Boff, Como fazer Teologia da Liberlacao, ed. Cit, ep. capl II

23. "Un leoslogo no vive en las nuben, oino que forme parte de la Iglesia y de la socieded, las cuales, unto h tun como le ours, no son cuerpos homogéneos, sino que se ver atrvesados por endencins, intereses y conflicios. Como culquier egente social y eclesial, el teologo coupa un determinado lugar y su producción leorica y su príctica gunrian una ciern funcionalidad par con tal o cun grupo de la Iglesie o la sociadad, ya rea apoyando, criticando, condenando o justificando. Este situnción objetiva y no depende de ln voluntad de las penonas. Sin embargo, el teblogo que he tomado conciencia del fenóneno puede controlar y orienter dichs funcionelided. Es una autertica ingenuided epistemológica prenteder hacer un discurso tebrico totalmente neutro, descomprometido y exclusivamente toologion" (Leanario Boff, Iglesia: carisma y pader. ed. cit. 30-31).

24. Mediación en el centido de instrumento, medios de construcción leologien. Ver Leonardo Boff, "Teologh de la liberación: lo minimo de lo mínimo," en Cuadernos de Nuestra América, 1986, 5. Le Habane, 223-2236. Tanado de Leonardo y Clodovir Bolf, liberlad y liberación, Salnmenea: ED. Sígueme, 1982, 13-28. Tambitan an Como fazer..., 40-55.

25. Teología de La liberación, 370.

26. Como fazer..., "Soliderizarse con el pobre es adonar a Dios y comulgar con Cristo," 6668.

27. Op. cit en notn 22, 40 .

28. "Đ turmino 'pobre' puede parecer, edembs de impreciso e intreclesial, un pocos sentimental y, finelmente, setptico. E 'pobre', hoy, es el oprimido, el marginedo por la socieded. el proletario que lucha por sus mb́s elementules derechos, la clases sociel explotada y despojadn, el pais que combate por su libención. Lo solidaridad y protesta de que hablemos tienen en el mundo aqual un evidente e inevilsble andeter 'político, en tento que tienen una significación libendon. Optar por el oprimido es optar contra el opresor" (Gustavo Gutitrez, Tologla de la liberación, 371-72). 
29. Ya con numerosos las trabajoe de relecture de la Eecriturs producidos por in TL. En cumto a la espinimelided, ver Gurtavo Gutierrez, "Una espirinnlided de la liberacion," en Teologia..., 253-260; Beber en su propio pozo. En el itinaroio erpiritud de m pueblo, Lims: CFP, 1983, 208; ¿"Que a expivinlided?," a Diakonia, 1985, 33, 2-10; entre

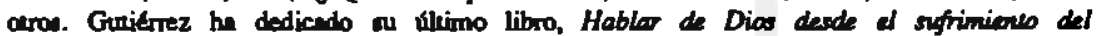
inocente (Lims: CEP, 1986) a reflexionar sobre (y desde) el "Libro de Job." Un ejemplo de ease reflexiones: "Ademis, la contruccion misme de una wocieded juen requierc un impulso y un clime que tricarnente la gramidad puede dar. Efectivamenie, no se trit de enfetizar lo lúcido y gratuito conere lo justo, timo de hacer que el mundo de la juaticia encrentre su pleno eentido en el umor libre y toth de Diou" (pp. 209-210).

30. La Biblin se vuelve lecture del catolico, no w6lo del protentante, y a estudio es promovido por les CEB y oure agnpaciones edesialen. El "Exado" es el libro preferido del Antiguo Tertemento, as camo los litros profticos. Del Nuevo Ternmento, los evingelios, "Hechos de los eportolea" y el Apocalipair." Los evengelios con los mí manejedo, como toce al lugar centril que la ensefianza y la pernondided de Crito tienen en la TL y los movimizras populnes crixinnos.

Por su parte, la fuerzen represiven han llegedo a identificar como un indice de peligrosided la venencie de biblins, en varios lugares de Centromerica cobre todo.

31. Teologib de la ..., 59-60.

32. Ibid, 60.

33. Ya son innumenables los cestimosios de exe profundo movimiento renovedor dedos por miles de cristinnos latinomericanos. Constituyen en ou canjunto un renlided y umn fuerza morl parz la $T L$ y en Centromérica te ha llegado a acamular un conjunto de experiencias pricticas y eatin en curso procesos de liberación con participación crintinna dentacad, que no podran dejar de influir en medida muy importante en el cristimismo del continente.

34. "Le verded es el nombre dado por la commidad histórica a aquellos actos historicos que fuern, son y cerin eficaces par la libereción del hambre," alime Hugo Asamann relecionando fe, praxis, criterio de verded, histori y libersción, ver Opresión-Libereción. Desafio a los cristianas, publiondo por Tieme Nuev, Montevideo, 1971. Tanndo de Oliveos, op. cir., 178.

35. "La conversion evangelice exige mát que un ctumbio en el conzton, exige tambien uns libención de la organización socil que produce y reproduce comportsmientos pecaminosas" (L. y C. Boff, Como fazer..., 88).

36. Desde la perspective de la $T L$, Enrique Dussell publico Historia de la Iglesia en América Latina, en Barcelonn, 1972; enter habin publicado Amsrica Latina y conciencia cristiana, Quito, 1970. Pablo Richned, La Iglesia lasinamericana entre el temor y la esperanza, Costa Rica: DEI, 1980; J.O. Beomm, Hisoria de Igreja no Brasil, Perrotpolis, 1980, y odros.

37. Por ejemplo, "Teologin y ciencin socieles", de Gustuvo Gutiérez, publicado en varias reviras criatimas. Cito a le Revira Larinoamerioana de Teologia, 1984, 3, 255-274.

38. Aunque puede pensarse lo contrasio respecto al orden de los peligros: "El marxismo puede paser de mode, pero la tentación secularise es mbs profunde y sin dude encontrara nuevas formao de presentarse" (Julio Terin Durari, "Acercamiento a la teologí de la liberacían" (II), en Mensajero, 1985, 703, 10).

39. "La reflexión sobre el misterio de Dios (eso es une teologin) s6lo puede hacerse desde el seguimierlo de Jesis" (G. Gutierre, Beber en su propio pozo, ed, cit, 204). Le cristologla es desarrollada o transitada por lodos los autores de la TL que hemos consuludo. Por lo dembs, es un lugar central de todo el pensamiento cristiano, y he sido fuente de las mis encendidas polénicas desde los primeros siglos del cristianismo.

40. Los autores más conocidos de la TL en el teme cristologion son Leonardo Boff (Jesuetisto Liberador, Petropolis, 1971) y Jon Sobrino (Cristologra desde América Latina, México: CRT, 1976). Gustavo Guritrrez, lo Ingo de su obm, desde Teologí de la liberación 
(cobre lodo he pare canrth, primere ceccifn, "Fe y hambre mevo") hare la "Conclusion"

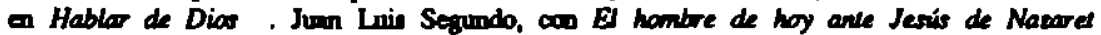

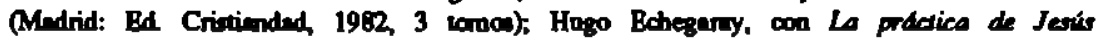

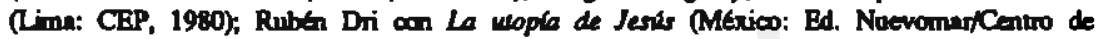
Bctudios Bcrontricon, 1984), y otron.

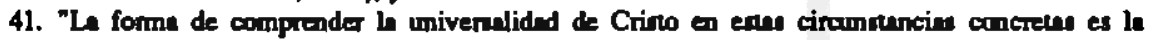

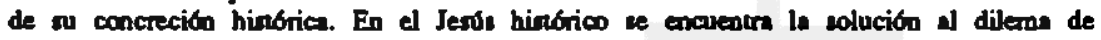
hacer de Crito una abatraccín o de funciannlizuto inmedimment" (J. Sobrimo, op. cif., 18; citado en Oliveron, 417)

42. "En primer lugur, mf que de la fe de Jesís, en oposicion a une posible incredulided, ent interesadn (la TL) en la hinoria de ess fe, pues on eas historia ve un panleliomo con la vitunción real del croyente El probleme de tute no consiste en elegir entre fe e incredulided (probleme mis uficomente europeo), sino an la problemitica del paso de una fe herededn abutract a une nueva fe liberdor" (J. Sobrino, ob. cil, 67-88; ciudo en Oliveros, 425).

43. L y C. Boff, Como forer..., 77-78.

44. Varios autores han renlizado estudios sobre Palestina en el siglo I. de C., en los cuales lat extructums de la economin y lo política, las elnes eocisles y sue representeciones se exponten con noteble rigor, y se relecionen con la pertonalided de Jesút, un procedencin y su actnacion. Le vilizacion que han hecho del conocimiento cientifico social, y especfionmente el marximo, ha mativado tmbien criticas fuertes en el seno de la Igleair.

45. "La fe no es la paserión de Dion y au reinado, sino la buiqueda de ellos" (R. Oliveros, op. cit., 426, explicando el capimulo IV de la obn de Sobrino).

46. L y C Boff, Como fazer..., 88.

47. "Enviendo a to Hijo, el padre 'aposto' por le posibilided de une fe y une conducte mareadas por la grawidnd y le exigencin de establecer la justicis. Siguiendo las huelle de Jesía los 'perdedores' de la historis como Job- eatín haciendo que el Sefior gane su queste" (Gustuvo Gutienre, Hablar de Dias, 205).

48. Es lo que hace, por ejemplo, Pablo Richerd, anando defune un modo deteminado de relación Iglesis-sociedad, al cual llame lo cristiended, como la forma de inserción de la Iglesin en la sociedad que otiliza como medinción el poder pollíco y social de las clases dominutes (ver La Iglesia lasinoamericana enire el semor y la esperanza, sobre codo los capítilos 4 y 5).

49. Con ayuda de las ciencias sociales se profundiza en la comprensión de la religiosidad misma y sus formas organizadas e implicaciones cociales.Es el caso, por ejemplo, de Ono Meduro, en su libro Religion y luche de clases (Caracas: Ed Aveneo, 1979), quier conopanaliza los requisitos pan que in visión preponderantemente religioss del mundo de los enupos socieles subaltemos pued tender a curnplir una función revolucianaris, influyendo en los terrenos de la conciencia de clase, la organización de clase y la movilización de clase. Parn que ase infuencia se logre, la religión de las clases explotadas debe expresar su contradicción fundamental con las clasea exploudoras, y umbien "conservar una ciers continuidad con las tradiciones de la misma clase (y, sobre todo. con las trediciones religiosas de ella)." Tomado de Pablo Richard, quien utiliza también ese marco tesrico en su "Religiosided popular en Centroamérica," en Religión y polúica en Amériea Central, Sen Jost: DEI, 1982.

50. "El compromiso con los pobres y los oprinidos y el surgimiento de las comunidades de base han ayudado a Ia Iglesis a descubrir el potencial evangelizador de los pobres" (Pueble, 1147).

51. Gustavo Gutitrrez, "La fuerza histórica de los pobres," XXXVI, an Signas de lucha y esperama, ed. cit

52. 'La mejor manera de evangelizar a los pobres consiste en permitir que los propios pobres se hagan Iglesia y ayuden a toda la Iglesia a ser realmente pobre y de pobres. En razón de 
ello comenzem a surgir, un poco por tods pares en Amtric Latins, millere de comunidedes eclesinles de base, circulon biblicos y una verdeder partorl popular. En ertas commidedes bo cristimos fueron descubriendo la comenion como al valor teolbgico estructurador y estructurnte de le Iglesian" (L. y C. Beff, Como farer..., B4).

53. La obre de Leonurdo Boff, Iglesia: carisma y pader, subtinulada Enseycas de eclesiología

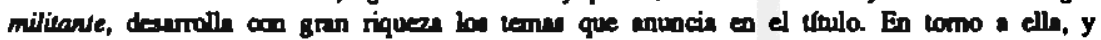

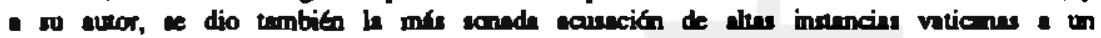
teblogo de la liberación; las manifertaciones del cardenal Ratzinger, prefecto de la congregación vationna pare la doctrine de la fe (del Sento Oricio haste 1975), en 1984, la llensa a Rama de Boff y demis detellea won conocidon.

Boff utiliza la eociologin, la economin y otrat ciencins cocinles; hable de capinal simbolico, medion de producción religiose, de modon de produccion disiméricos (sociedndes de clases) en cuyos medion crecio la Iglevia reproduciendo un proceso de concenuración del poder religioso, "un proceso de expropiación de los medion de producción religioso por parte del clero a costn del pueblo cristimo," etc. También precisa con agudeza, desde la simación bresilefie, el concepto de tincretismo y adviere clanmente los peligros del inmovilimo instimcional: "En A. Latina y en Brasil tenemos que hacer une teologin de urgencia. De lo controrio perderenos el tren. Nos suplemtark la conme vinalidad religioss del pueblo, recurestrad por otros grupos ajenros a la Iglesia catolica..." (Tomedo de "Respuese a Rnizinger," 362-363).

54. "¿Cúl es le forme instiucional que Jests quiso pare su Iglesia? ...quiso y sigue queriendo aquella que la comunidad epostólice, iluminede por la luz del Esplritu Santo y confrontade con las urgencias de la simacion, decide y asume responsablemente" (Leconardo Boff. Eclesiog fresis..., at cil, 94).

55. Gustvo Gutierren, Teologg..., 347. Gutiérez continú, "Sob ese compromiso puede haces de ell un sumbntico signo de unided Ess unided transith hoy, en particular on America Lalina, a traves de la opción por los oprimidos... la Iglesis misma se iŕ haciendo un en este proceso histórico y en este compromiso por la libención de los marginedos y explowes."

56. Gutiérez recuerda la declanación públice de Camilo Torres al pedir al cardenel Concha Cordobs "... que me libere de mis obligeciones clericales par poder servir al pueblo, en el terreno tempord. Sacrifico uno de los derechos que amo mis profundamente: poder celebrar el rito extemo de la Iglesia como sucerdole, parn crear las condicienes que hacen miss autention el culvo...Pero in comunidad cristinne no puede of recer en forma auténtica el secrificio si antes no he realizado, en forme efectiva, el precepto del amor al projimo" (Ciro Camilo Torres. Paginas escogidas, Serie "Hambre de la Revolución," Universidad de La Habane, PCC, 1970, 227-228). Guritrez now: "El gesto de Cernilo hizo percibir despiademente una realidad coulte bajo una monteria de palabras y buenes intenciones" Teolog $6 . . ., 327$, n. 31).

57. "El quehacer reológico desde $-\mathrm{y}$ mís aún- por las clases explotedes, las razas desprecindas, las culturns marginedas mismas, es una parte del ejercicio de su derecho a la liberación... toda reflexión es una manera de tener poder en la historia; sólo una manera, es cierto, pero se trata de una verdadera centribución al poder necesario para transformar la historia, para destruir un sistema opresor y construir une sociedad humana y justa. Reflexionar sobre la fe vivida en la lucha, es la condición parn anuncinr al Dios liberador desde los hombres" (Gustavo Gutitrez, "Le fuerza histórica de los pobres," ed. cil, XXXVII-XXXVIII).

58. Gustavo Gutiérez, "Lyon: Debate de lo tesis de docer (1985)," en Pdginas, 1985, 71.72, Separain, 22

59. Gustrvo Gutienrez, Teologla.., 28.

60. Leconardo Boff, Teologia do cativeiro e da liberlaceo; "Respuesta a Rezinger," en Revisto Latinoamericana de Teologh, 1984, 3, 347-348. 
61. Leannido Boff, Teologin de lo liberncion: lo minimo de lo mlmino," ed. cih, 235.

Boff hace exposicito concin y rica de L TL en Iglesia: carisme y pader, capínlo 2 , eplgrefe 7, "Sexu tendencin teologica: In leologin del cautiverio y de la liberación" (od. cit, 40-42).

62 En 1971, Gutuvo Gulierre escribls: "...de hecho, la teologis contemporinea se halla en insoslayable y lecundn confrontación con el marxismo [...]. Falta, sin embargo, una confrontación tébrica y príctica de alto nivel que deje los caminos trillados del 'dílólogo' e imove creadoramente" (Teologí..., 25-26 y n. 33).

63. "Por consiguiente, la revolucion no colo es neccsurie porque la clase dominante no puede er derrocade de aro modo, ino umbitn porque únicamente por medio de une revolución logrart la dase que derriba ualir del cieno on que se hunde y volverse capaz de fundar la

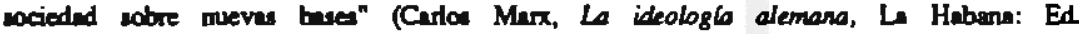
Revolucionaric, 1966, 78. En el mimo centido, ver Teris sobre Feuerbach, No. 3, prigines finclea de Miseria de la flosofia, etc).

64. En 1965 escribla Emesto Che Guevar al director de Marche de Montevideo: "DEjeme decirte, aresgo de parecer ridlaulo, que el revolucionario verdadero eqú guiedo por grandes centimientos de amor. Es imposible pensar en un revolucionario auténtico, sin eatn canlided... Nuestros revolucionarios de vanguardia tienen que idealizar ese amor a los pueblos, a la causas mis sagrada y hacerlo único, indivisible" ("El socialismo y el hombre en Cubs," En Emerto Che Guevare, Obras, 1957-1967, La Habana: Casa de las Americas, 1970, T. 2, 382. Este antaulo es umo de los mis importantes textos marristaleninirtin que se han ecrito an Amtria).

65. A low 26 afion, yn Mard tiene clane conciencie de esto: "pan superar la idea de la propiedad priveds es plenumente suficiente la iden del comunismo. Pero para superar la propieded privad real, hace faln la acción real del commismo. L historia se encargard de llevarlin abo, y ese movimiento que mentalmente nos representumos ya como auroapencion, tendrt que recorrer en la realided un proceso muy duro y muy largo." A continusión, Marx celebre can un progreso efectivo el poder tener yt, sin embargo, conciencie de ese movimiento historico, "y uma conciencis, ademas, que se eleva por encim de a," ver Manuserisas económicas y filosbficos de 1844, Le Habann, Editon Politica, 1965, 130.

66. Mntr mismo insistió bartante en le distinción enire clases $e$ individuos en su concepción ceoricas, y la consecuencins que hay que extrer de ese distinción en el terreno de las valoneciones. En in presenteción de la obn mis importunte de su madurez, cuyo primer torno pado publicar en 1867, aclarn que e refiere en ello a los capitalistas y termenientea, wolo "en cumto perronificación de categorias econfmicas, como representantes de deserminados imerases y releciones de duse Quien como yo concibe el desertollo de le formeción econotnica de la socieded como un proceso histórico-nerunl, no puede hecer al individuo repponable de la existencir de relaciones de las que al es socialmente criamra, anque mubjetivernente se cansidere muy por encima de elles" (EI copital, La Habana: 1962 T. L, Prologo de Marx a la primen edicion, XXIII).

67. Lenln lo unbrin bien. Desde las dnmiricas discusiones alrededor de la paz de Brest (¿Creen que el cemino de ln revolución estl sembrado de rosas?... Asl seria fácil ser revolucionsrio") hasta wu escritos postreros, cano "Nuestre revolución" (1923), Lenín

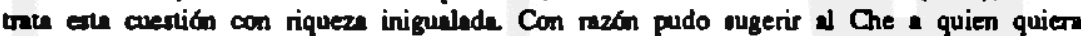
estudin marxismo que debe leer hasta el ultimo papel que escribió Lentn desie la toma del poder hace el fin de su vide.

68. En centenares de discursos, en escritos, entrevistas y declanciones, Fidel Cestro ha manejedo wdot exos concepton cano expresión coherente de las posiciones marxistaleniniras y comuniats, a lo lago de le hirtoris de la revolucion cutane, al talar las crestiones min importantea de la lucha, la construcción socialiste y el internacionalismo. Pare buccar ejemplos a6lo en los congresos del Partido Comuniste Cubano, recordemos el apinulo X, "EL Partido," del Informe Central al Primer Congreso, o el úlimo pirmafo de 
equel Informe; o ln "Introducción" al Informe al Segundo Congreso.

Con motivo del terver congreso pudo verse por wode Cubs un afiche politico que terin corno leme una frace del Informe al Primero: "El Partido es hoy el alma de la revolución cubme:

69. Dou ejemplos mury destacados entre muchos: el sucerdote guerrillero de Nicaragua, Gaspar Garcla Lavinna, comandante del FSLN, muero en combate el 11 de diciembre de 1978. Entre su poema, uno brevinimo y profundo: "A morir, a morir/ guerrillero:/ que par aubir al cield hay que morir primero." El arzobispo Oscar Amulfo Romero, de El Salvador, sesesinado el 24 de marzo de 1980. Romero, quien vio venir "un cristianismo consciente," denunció con fumeza ejempler lns curses estructurales de la miseria y le explotación, y la represión inlvaje contra el pueblo. "Le voz de la sangre es le mís elocuente de la pulnbre," dijo. "...Si me mann resuciurt en el pueblo salvadorefio."

70. Entre nosotrou ae desten sobre lodo lo entrevista de Frei Beno a Fidel Castro, Fidel y la religion, La Habren: Oficina de Publiceciones del Consejo de Estado, 1985. Cimpos de miles de ejemplares se vendieron en Cube, $y$ ha tenido grm acogidn en Brasil y en otros paives del continenie.

71. Sequende Congregacín pan le Doctrin de la Fe, 6 de agosto de 1984.

72. Ambes inaruociones pueden encontrare en Paginas, 63-64 y 77, entre otres publicaciones.

73. Ver los comenurios de Ignacio Ellecurta, Jon Sobrino, Gustavo Gutierrez, Leonardo Boff y Real Fome-Betmocurt on Diatonia, 1986, 38. En Pdgiras, 1986, 78, hay un anflisis de Francieco Moreno Rejón y oro de Gustavo Gunierrez Y Pablo Richard, "El Varieano. el Pape y le TL Intinoamericme," en Pasos, 1986, 7, 14. Gustavo Gulierrez, La verdad los hard libres, Limn: CEP, julio de 1968.

74. El terio completo en Diakonio, 1986, 38, y en Páginas, 1986, 78.

En ou virie a Colombin, el Pape repitio públicamente que la TL "es útil y necesaria" (2 de julio de 1986), em vez en la rede del CELAM, en Bogoll

75. Conntinúm apareciendo, por an parte, las contribuciones intelectuales de los teólogos. Adem', a fmes de 1985 comenzo le publicación progresiva de una colección que debert tener 55 volímenes, Inmadn Teologia y liberación; en ella trabajan mín de 100 teólogos y ce presende proveer al a agentes de pastorl y demás interesedos de un conjunto articulndo del penamiento cristinno de libración. Los editores son Vozes de Petropolis y Edicioner Pauline, de Buenos Aires y Madrid.

Un grupo numerono de revistas cristinna publice arficulos y ofrece otros materinles desde lon puntos de viste de le TL Ella virven de vehiculo inmbién a numerosos centro de reflerión y formación de agentes de pastonl y cuadros de los movimientos popularea crivtinnos, los cuslea participan muchas veces en sctividades de promoción social con organizaciones populara.

76. Un caso reciente en ou quinen anciclica, Dominum ef vivificantem (Seffor que da vida), de mayo de 1986, dedionde al Esplrio Santo en le vida de In Iglesis y el mundo. En ou tercere parte critica dur y expresamente al marxismo, reduciéndolo a un materialismo vulgar que pretente eliminar in religión "por los métodos más oportunos según los beras y circunsuncial" 